\title{
Computational modelling of bovine ovarian follicle development
}

\author{
Dagmar Iber ${ }^{1 *}$ and Christian De Geyter ${ }^{2}$
}

\begin{abstract}
Background: The development of ovarian follicles hinges on the timely exposure to the appropriate combination of hormones. Follicle stimulating hormone $(\mathrm{FSH})$ and luteinizing hormone $(\mathrm{LH})$ are both produced in the pituitary gland and are transported via the blood circulation to the thecal layer surrounding the follicle. From there both hormones are transported into the follicle by diffusion. FSH-receptors are expressed mainly in the granulosa while LH-receptors are expressed in a gradient with highest expression in the theca. How this spatial organization is achieved is not known. Equally it is not understood whether LH and FSH trigger distinct signalling programs or whether the distinct spatial localization of their G-protein coupled receptors is sufficient to convey their distinct biological function.
\end{abstract}

Results: We have developed a data-based computational model of the spatio-temporal signalling processes within the follicle and (i) predict that FSH and LH form a gradient inside the follicle, (ii) show that the spatial distribution of $\mathrm{FSH}$ - and LH-receptors can arise from the well known regulatory interactions, and (iii) find that the differential activity of FSH and LH may well result from the distinct spatial localisation of their receptors, even when both receptors respond with the same intracellular signalling cascade to their ligand.

Conclusion: The model integrates the large amount of published data into a consistent framework that can now be used to better understand how observed defects translate into failed follicle maturation.

Keywords: Ovarian follicle development, PDE model, Computational biology, Bovine

\section{Background}

Ovarian follicular development has been studied for decades and has allowed major progress in animal breeding and assisted reproduction in the human. Many animal models of folliculogenesis are in use [1], partly in their own right to help the advancement of breeding and partly as models for human reproduction. Because of the bulk of published data dealing with bovine folliculogenesis and its great similarity to its human counterpart [2] we focused here on the bovine as a model system. As humans, horses and some sheep breeds, the cow is a mono-ovulatory species [3], i.e. one dominant follicle is selected from a cohort of 5-30 follicles [2,4]. All other recruited follicles undergo atresia [5]. The number of early growing follicles slowly declines with increasing age. Key regulators of follicular selection and maturation are the gonadotropins

\footnotetext{
${ }^{*}$ Correspondence: dagmar.iber@bsse.ethz.ch

1 Department for Biosystems Science and Engineering (D-BSSE), ETH Zurich,

Swiss Institute of Bioinformatics, Basel, Switzerland

Full list of author information is available at the end of the article
}

follicle-stimulating hormone (FSH) and luteinizing hormone (LH), both secreted in the pituitary [5]. While the initial, slow growth of follicles is independent of these gonadotropins, further progression to the antral follicular state requires FSH [6]. FSH induces the expression of a wide range of genes, including those of the LH-receptor and the aromatase, an enzyme that converts androgens into estrogens [7]. Within the follicle the regulatory interactions result in a complex network (Figure 1), with many of the components restricted spatially.

In spite of much detailed data, an integrated understanding of the processes regulating folliculogenesis is still lacking, and given the many incoherent feedbacks, several experimental findings appear counterintuitive. Theoretical models bear the potential to integrate large amounts of information into a consistent framework. A number of theoretical models have already been developed for ovarian follicle development (for a review see [8]), but only few models explore the processes within the follicle. Given the large size of both human and bovine follicles 


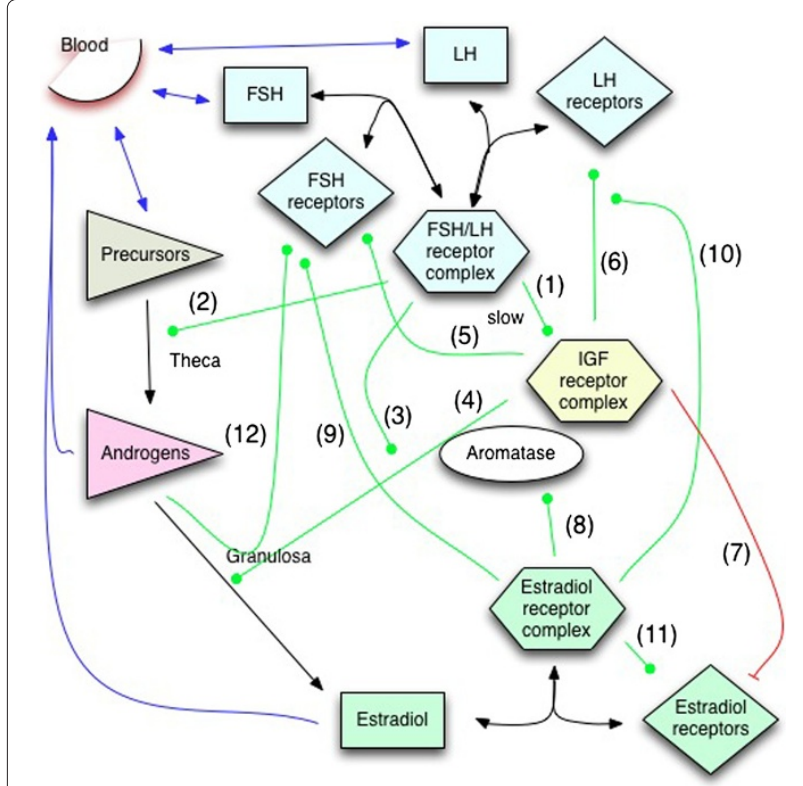

Figure 1 Regulation of follicular development. The modelled signalling network. In brief, FSH- and LH-signalling enables IGF signalling in several ways (arrow A1), and enhances the production of androgens (A2), as well as the production and activity of aromatase (A3), the enzyme that catalyzes androgens into estradiol. IGF signalling is necessary for the gonadotropin-dependent expression of aromatase (A4), enhances the production of $\mathrm{FSH}$ and $\mathrm{LH}$ receptors $(A 5, A 6)$, and reduces the expression of estrogen receptors (A7). Estrogen signalling enhances the production of aromatase (A8), as well as the production of the receptors for FSH (A9), LH (A10), and estradiol (A11). FSH receptor expression is observed also in the absence of $\mathrm{FSH}, \mathrm{LH}$, and estrogen signalling, and we therefore introduce a further regulation-independent component $\vartheta$, which may represent testosterone-dependent signalling (A12). Blue arrows indicate exchange with the blood, black arrows indicate chemical reactions (binding or catalysis), green arrows indicate activating impacts and red arrows indicate inhibitory impacts. All components also decay, but for greater clarity decay reactions have not been included in the scheme. For a detailed description of the network interactions along with the evidence see the main text.

$(15-20 \mathrm{~mm})$, gradients are likely to form, and transport by diffusion may become limiting as indeed noted in models of oxygen transport in the follicle [9-11]. Since many of the signalling components are produced only in isolated parts of the follicle, with some diffusing and others being cell-bound, also spatio-temporal signalling gradients can be expected to emerge that may play an important role and may explain some of the counterintuitive data.

We therefore sought to build a reaction-diffusion model that would describe the signalling dynamics of the regulatory interactions between FSH, LH, estradiol, androgens, and insulin growth factors (IGF) in space and time. Quantitative data is available to determine virtually all parameter values, and the model is consistent with published data. The data-based model can be used to explore the patterning mechanisms inside the follicle, and to understand the molecular causes and effects of alterations observed in infertile patients.

\section{Methods}

\section{Model development}

Follicle development in the cow has been described in great detail $[3,12]$ and much data is available to base the model on. We will focus on the development of the dominant follicle and leave the follicle selection process to future work. We aim at developing a parsimonious model for the process and thus seek to keep the regulatory interactions as simple as possible while reproducing the measurements. We focus on the hormones FSH $(F)$, LH $(L)$ and their receptors, on androgens $(A)$ estradiol $(E)$ and the estrogen receptor for steroid-dependent signalling, as well as on IGF signalling $(I)$. The aromatase is not explicitly included in this parsimonious model because its activity can well be approximated as the direct result of IGF signalling and regulation through FSH and $\mathrm{LH}$ as discussed in detail below. Receptors of FSH, LH, and estradiol will be denoted $R_{i}$ and the receptor complexes $C_{i}$, with $i=\{F, L, E\}$. The modelled core network that regulates the development of the follicle is shown in Figure 1. Before we discuss the regulator interactions in detail we first introduce the geometry of the computational domain.

In contrast to human follicular development [13,14], the thickness of the granulosa layer of the bovine follicle has not yet been measured during its growth. Given the rotational symmetry, the fast mixing in the follicular fluid, and the lack of more detailed data, we restrict the model to a 1D cross-section through the follicle as illustrated in Figure 2A-D. Experimental measurements show that growth of the dominant follicle is about linear with time $[15,16]$. We can therefore approximate the growth process as a uniform expansion of the domain such that the length $\Lambda(t)$ of the domain relates linearly to time, i.e.

$$
\Lambda(t)=\Lambda(0)+v \times t,
$$

where $v$ is the growth speed of the domain. The domain is set to $x(t)=\Lambda(t) \xi$ where $\xi$ denotes the stationary coordinate frame $\xi \in[-1,1]$.

At the beginning of follicular development the oocyte resides in the center of the follicle, surrounded by granulosa and theca cells (Figure 2A). At later stages a fluidfilled antrum emerges and the oocyte is thought to become located more at the periphery of the antrum of the follicle (Figure 2C). We will simulate both situations and discuss the impact of the fluid-filled cavity and the biased localisation of the oocyte. Certain reactions differ in the compartments. We therefore need to define compartment boundaries in the simulation. The thicknesses of theca and granulosa have been reported. In the first set of simulations we will only consider granulosa and theca 


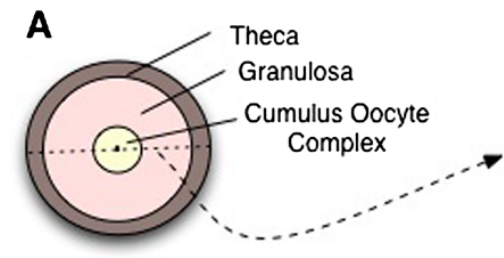

C

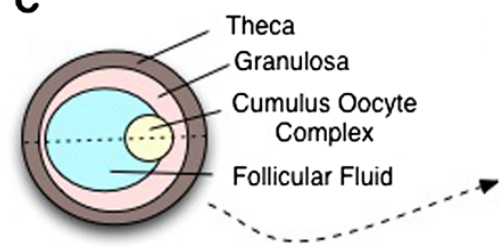

B

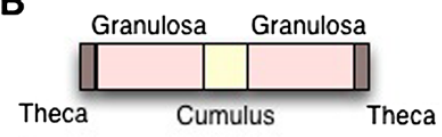

D

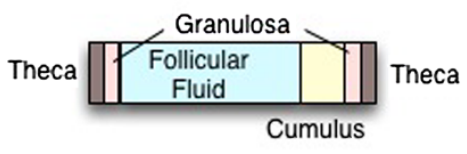

Figure 2 The Geometry of the ovarian Follicle. (A) In the follicle the oocyte is embedded in somatic tissue. The innermost layer are the cumulus cells (yellow) followed by a layer of granulosa cells (pink), and an outer layer, the theca (brown), that is enervated by blood vessels. Formation of androgens is restricted to the theca, while the formation of estradiol is restricted to the granulosa cells. (B) The computational domain represents a 1D cross-section of a follicle and expands over time. The outer part of the domain (brown) is the theca, the intermediate layers (pink) represent the granulosa; cumulus cells and the oocyte are in the center (yellow). (C-D) A more refined computational domain that also includes the follicular fluid (blue) on one side of the cumulus oocyte complex.

(Figure 2A). Accordingly, we only need to define the position of the compartment boundary between granulosa and theca. The antral bovine follicle expands from a diameter of about $5 \mathrm{~mm}$ to about $20 \mathrm{~mm}[15,16]$. The thickness of the theca interna measures only about $75 \mu \mathrm{m}$ in the dominant follicle, and the thickness of the theca remains constant [17]. The exact thickness of the theca is not relevant to the model because the blood flow determines the concentration of the soluble factors in this compartment and their distribution is therefore not diffusion-limited; the measured serum concentrations were reproduced by adjustment of the relative gain and loss rates. We can then make the simplifying assumption that the thecal layer scales over time, such that the border between the granulosa and the thecal layer stays at a constant position on the stationary domain, $\xi_{\theta}=1-2 \times 0.1 / 20=0.99$. To show that this assumption is valid we include the plots, which are shown in Figures 3, 4, 5 and 6, with a 20\% thicker thecal layer in the Supplementary Material (Additional file 1: Figure S1, Additional file 2: Figure S2, Additional file 3: Figure S3 and Additional file 4: Figure S4), using the same parameter values as before (Table 1). As can be seen, only the concentration of androgens, which are produced in the theca, increases significantly as the thickness of the thecal layer is increased (Additional file 3: Figure S3); the overall gradient shapes remain very similar (Additional file 1: Figure S1, Additional file 2: Figure S2, Additional file 3: Figure S3 and Additional file 4: Figure S4). The small differences could be removed by adjusting the thecal production rates accordingly. The spatial restriction of reactions to theca $(\Theta)$ or granulosa $(\Gamma)$ (as shown in Figure $2 \mathrm{~A}, \mathrm{~B}$ ) can then be incorporated by the use of a Heaviside function $H$, i.e.

$$
\begin{aligned}
\Theta & =H\left(\xi^{2}-\xi_{\theta}^{2}\right) \\
\Gamma & =1-\Theta
\end{aligned}
$$

The quadratic term was included to represent the theca on both the positive and the negative $\mathrm{x}$-axis $(x \in$ $\Lambda(t) \times[-1,1])$.

When we include the follicular fluid in the simulations, the left part of the granulosa domain is reduced and follicular fluid is taking the space (Figure 2C). The antral bovine follicle expands from a diameter of about $5 \mathrm{~mm}$ to about $20 \mathrm{~mm}[15,16]$. The thickness of the theca interna measures about $75 \mu \mathrm{m}$ [17], and the thickness of the parietal granulosa is about $50-65 \mu \mathrm{m}$ in dominant bovine follicles $[17,18]$. The cumulus oocyte complex $(\mathrm{COC})$ in the mature, dominant human follicle measures about $3 \mathrm{~mm}$ in diameter. The remaining part is filled by the follicular fluid. We will not separately consider the granulosa cells that surround the oocyte as part of the COC, because, unlike in published research data dealing with human follicle development [19], such a distinction is not made in published research, on which the bovine model is based (i.e. $[15,16])$. The spatial restriction of reactions to theca $(\Theta)$, granulosa $(\Gamma)$ or follicular fluid $(\Phi)$ (as shown in Figure $2 \mathrm{C}, \mathrm{D}$ ) can then be incorporated by a combination of Heaviside functions as

$$
\begin{aligned}
\Theta & =H\left(\xi^{2}-\xi_{\theta}^{2}\right) \\
\Gamma & =H\left(\xi-\xi_{\phi_{1}}\right)-H\left(\xi-\xi_{\phi_{2}}\right) \\
\Phi & =1-\Theta-\Gamma .
\end{aligned}
$$

As before the theca domain is set to $\xi_{\theta}=0.99$. The granulosa layer adjacent to the theca is also very thin compared to the diameter of the follicle (which measures 

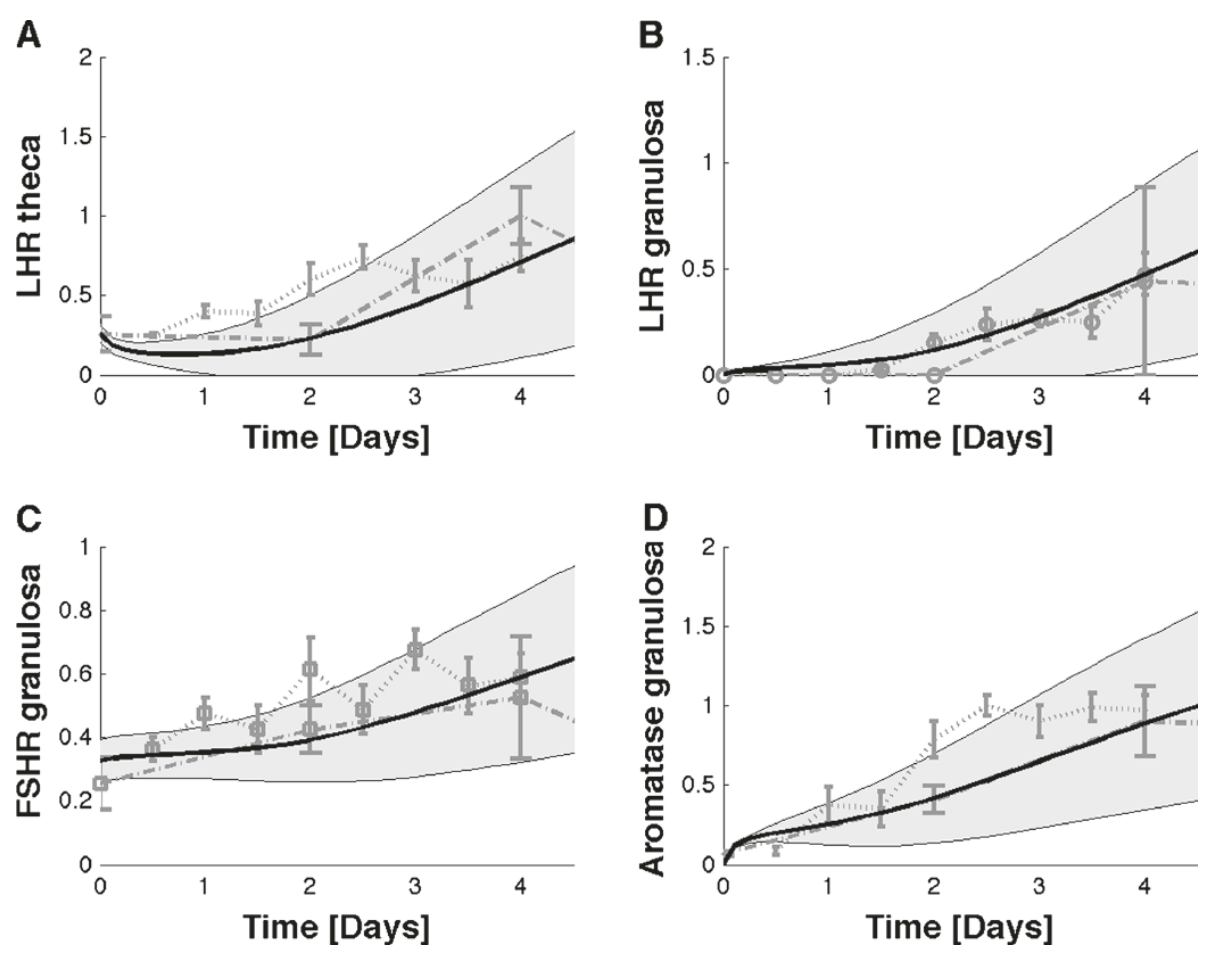

Figure 3 Time-dependent expression profiles in the follicle. Simulated and measured expression levels of LH receptor in granulosa and theca, and of the FSH receptor and the aromatase in the granulosa during the 1st wave of the bovine follicle maturation process. The data was recorded by $[15,16]$. The lower curves that extend to 10 days are the measurements in [16]; the follicles in these measurements were growing more slowly than in the study by [15]. Note that the dominant follicle undergoes atresia from day 6. (A) Data (dotted lines) and simulation predictions (solid line) of LH receptor expression in the theca. (B) Data (dotted lines) and simulation predictions (solid line) of LH receptor expression in the granulosa. (C) Data (dotted lines) and simulation predictions (solid line) of FSH receptor expression in the granulosa. (D) Data (dotted lines) and simulation predictions (solid line) of aromatase expression in the granulosa. The shaded area indicates the standard deviation of the simulations when noise is applied to the parameter values.

about $20 \mathrm{~mm}$ in diameter), and measures about 50-65 $\mu \mathrm{m}$ in bovine follicles $[17,18]$. Experiments reveal a broad distribution of follicular wall thickness in early follicles [18]. As the follicles grow with time, the distribution of follicular wall thickness appears to become more constant in the dominant follicles $[17,18]$, whereas the thickness of the regressing follicles decreases [17]. In the absence of more detailed data on the relative expansion of the bovine granulosa layer we will assume that this layer scales with the expanding follicle, i.e. $\xi_{\phi_{1}}=-\xi_{\theta}+0.1 / 20=$ -0.985 . This implies a granulosa thickness of $12.5 \mu \mathrm{m}$ in the small $5 \mathrm{~mm}$ follicles, which is at the lower limit of the observed distribution of granulosa thickness during early follicular growth. The $\mathrm{COC}$ in pre-ovulatory human follicles, which measure about $20 \mathrm{~mm}$ in diameter, is about $3 \mathrm{~mm}$ in diameter and is located adjacent to the mural granulosa. The follicular fluid fills the rest of the domain such that $\xi_{\phi_{2}}=-\xi_{\phi_{1}}-3 / 20=0.835$. All soluble proteins (but not the receptors) can diffuse into the follicular fluid. Given the absence of receptors in the follicular fluid, receptor-dependent degradation does not occur within the follicular fluid. Moreover, the, in comparison to the half-life of FSH, much shorter half-life of LH is attributed to unspecific cellular degradation processes that are triggered by the particular glycosylation of LH. Since cells are absent from the follicular fluid, we assume that $\mathrm{LH}$ is not degraded in the follicular fluid. Similarly, we assume that FSH, androgens, and estradiol are not degraded in the follicular fluid. This assumption is not critical for model conclusions because the concentrations in the follicular fluid can be adjusted by altering the production rates.

Since the hormones and their receptors can all diffuse within the follicle, if at different velocities, we formulate the model as isotropic advection-reaction-dispersion equations for a compound $c_{i}$ with diffusion coefficient $D_{i}$ and reaction terms $\mathcal{R}\left(c_{i}\right)$ :

$$
\partial_{t} c_{i}+\nabla\left(\boldsymbol{u} c_{i}\right)=D_{i} \nabla^{2} c_{i}+\mathcal{R}\left(c_{i}\right)
$$

where $\boldsymbol{u}$ denotes the external velocity field. Since we assume uniform growth on a 1D spatial domain we can solve a reformulated set of equations on a static domain $\xi=[-1,1]$ with $x=\Lambda(t) \xi$ : 

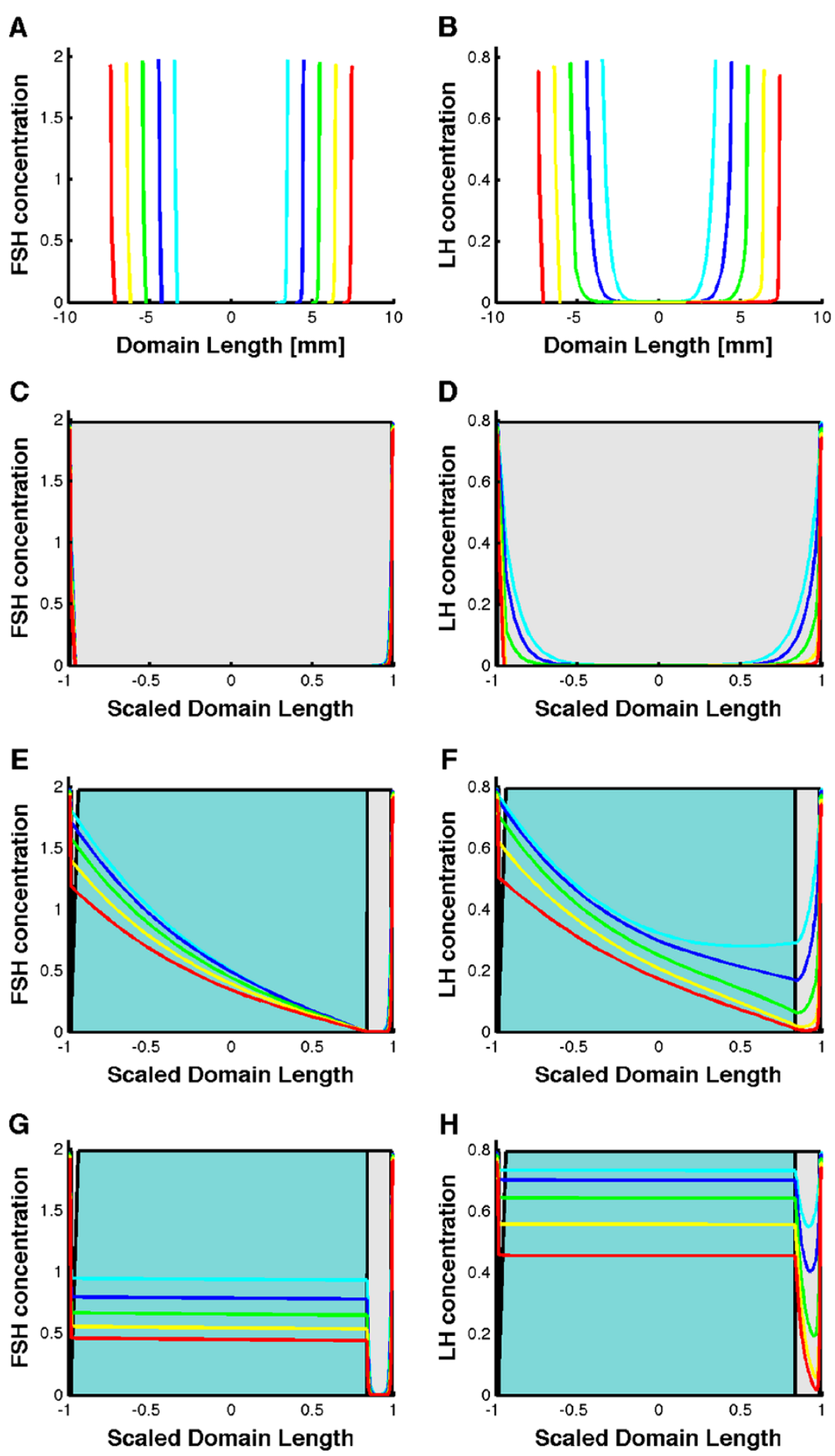

Figure $4 \mathrm{FSH}$ and LH gradient formation in the follicle. At time zero no hormones are present in the follicle (black line). Over the next five days $\mathrm{LH}$ and FSH diffuse into the follicular domain from the boundary (theca) and form a gradient. The five time points are equally spaced at 0 (black), 1 (cyan), 2 (blue), 3 (green), 4 (yellow), and 5 days (red) curves. Panels $\mathbf{A}$ and $\mathbf{B}$ show the profiles on the growing domain. Panels $\mathbf{C}$ and $\mathbf{D}$ show the concentration profiles on a scaled domain. Panels $\mathbf{E}$ and $\mathbf{F}$ show the concentration profiles on a scaled domain if we include the fluid-filled antrum on one site of the COC block. Panels $\mathbf{G}$ and $\mathbf{H}$ show the concentration profiles on a scaled domain if we assume rapid mixing in the fluid-filled antrum. The shading indicates the different parts of the follicle, i.e. theca (white), granulosa cells (dark grey), cumulus cells (light grey), and follicular fluid (blue). Note that the theca and granulosa layers are very thin and thus barely visible. 

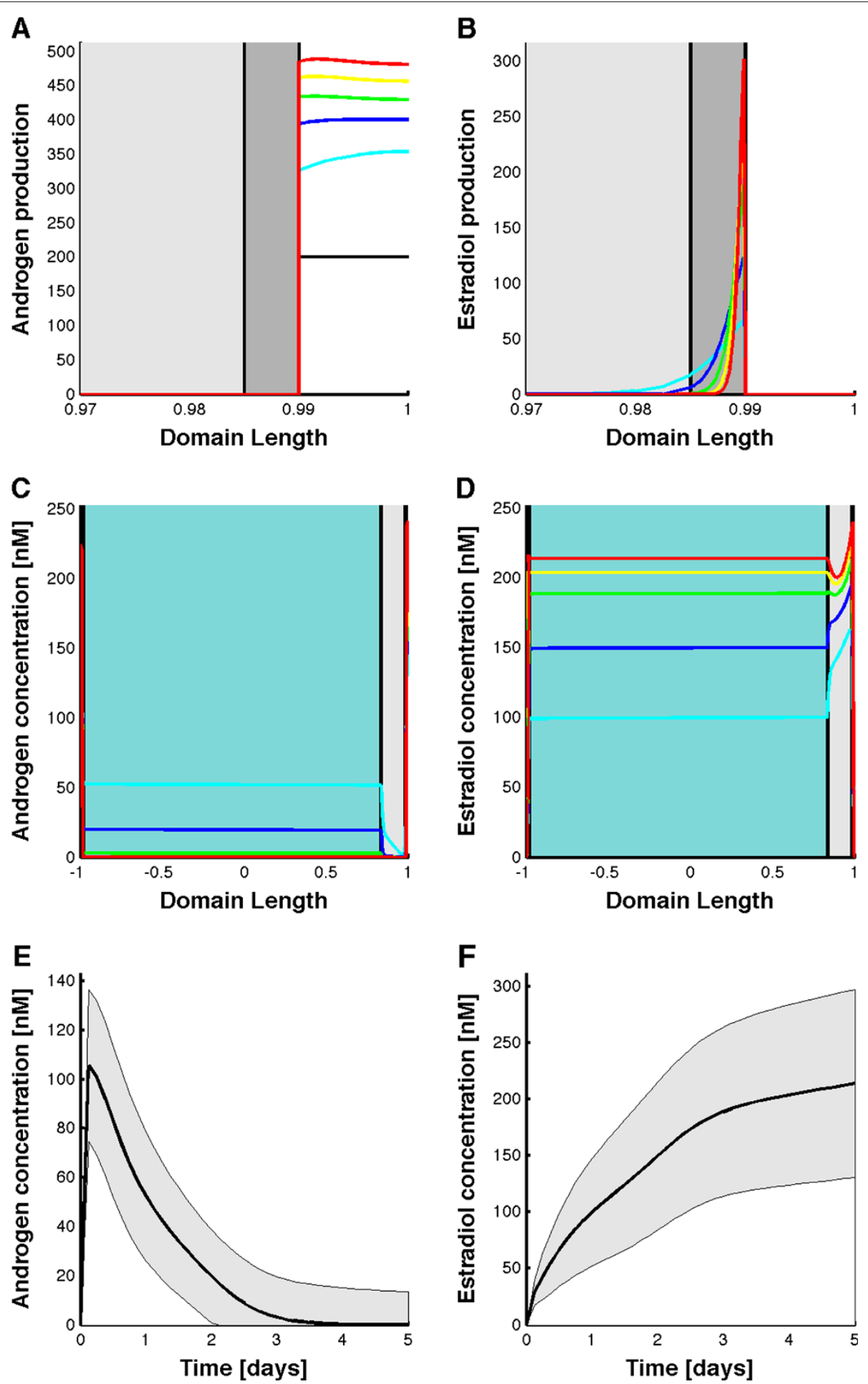

Figure 5 The production of androgens and estradiol in the follicle. (A-B) Production of (A) androgens and (B) estradiol. Only part of the domain is shown, i.e. theca (white), granulosa cells (dark grey), and a part of the COC (light grey). (C-D) Concentration profiles of (C) androgens and (D) estradiol. The five time points are equally spaced at 0 (black), 1 (cyan), 2 (blue), 3 (green), 4 (yellow), and 5 days (red) curves. All panels show the concentration profiles on a scaled domain. The shading indicates the different parts of the follicle, i.e. theca (white), granulosa cells (dark grey), COC (light grey), and follicular fluid (blue). Androgens are produced only in the theca, and estradiol is produced only in the granulosa cells. In the follicular fluid steroids are neither produced nor degraded. (E-F) The average steroid concentrations of (E) androgens and (F) estradiol in the follicular fluid over time. The shaded area indicates the standard deviation of the simulations when noise is applied to the parameter values. 

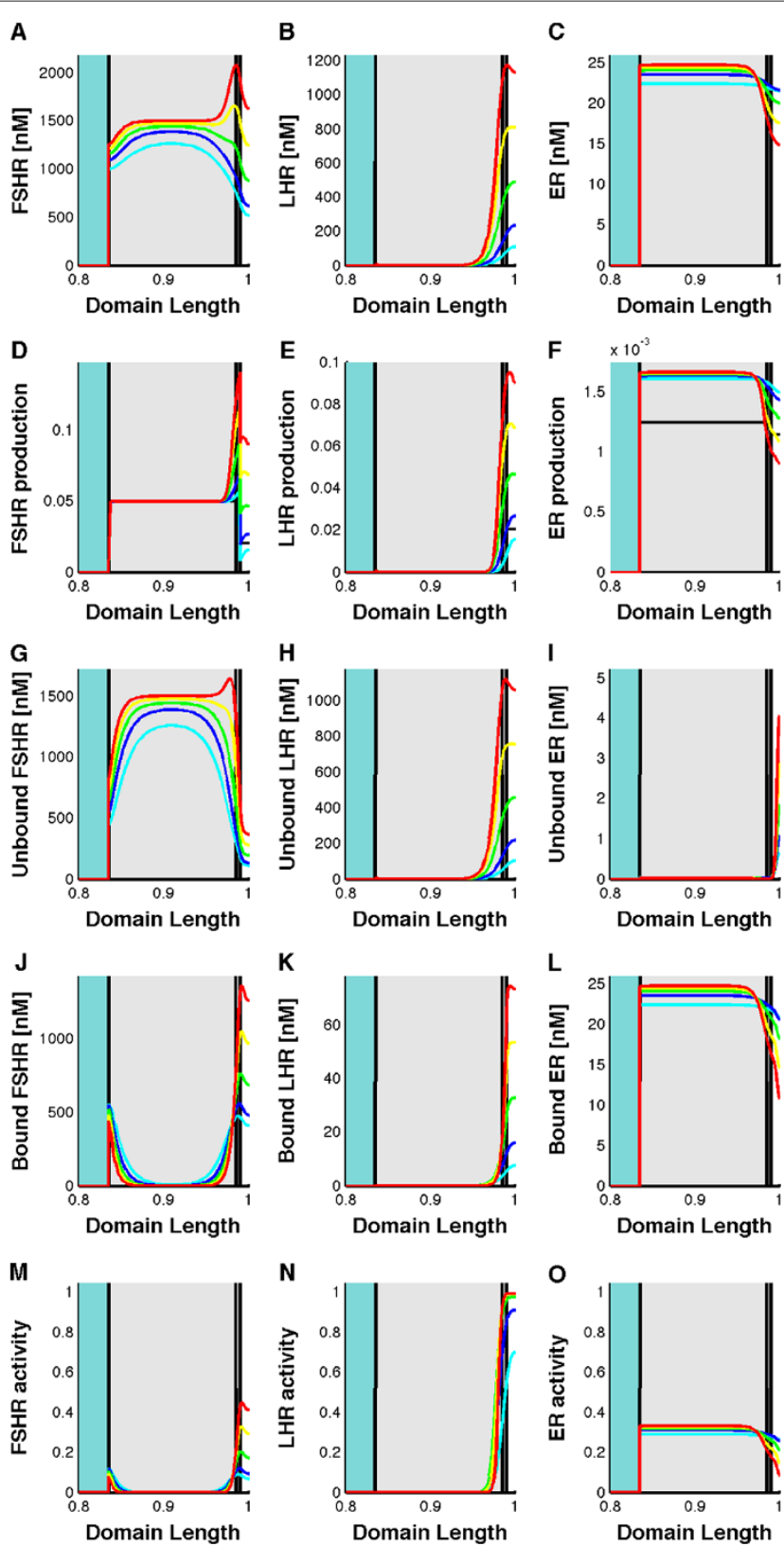

Figure 6 The emergence of FSH-, LH-, and estrogen receptor gradients in the follicle. (A-C) Receptor profiles of (A) FSH-receptor, (B)

LH-receptor, (C) estrogen receptor. At time zero the receptor concentrations are low and the receptors are distributed homogenously in the follicle (black line). Over the next five days localised feedbacks create a graded distribution of the receptors. (D-F) Receptor production. (G-I) Unbound receptors (J-L) Bound receptors (M-O) Receptor activity. The five time points are equally spaced at 0 (black), 1 (cyan), 2 (blue), 3 (green), 4 (yellow), and 5 days (red) curves. All panels show the concentration profiles on a scaled domain. For better readability we only show the subset of the domain that includes the theca (white area), granulosa (dark shade), COC (light shade), and part of the follicular fluid (blue shade) on the right hand side of the domain. The shaded area indicates the standard deviation of the simulations when noise is applied to the parameter values.

$$
\frac{\partial c_{i}}{\partial t}+\frac{v}{\Lambda(t)} c_{i}=\frac{D_{i}}{\Lambda(t)^{2}} \frac{\partial^{2} c_{i}}{\partial \xi^{2}}+\mathcal{R}\left(c_{i}\right) .
$$

The reaction terms $\mathcal{R}\left(c_{i}\right)$ of the components describe the regulatory interactions based on information from the literature. We consider four classes of reactions: production, decay, complex formation, and catalytic processing as is discussed in detail below along with an introduction of all parameter names. The final set of equations for the reaction terms $\mathcal{R}\left(c_{i}\right)$ are: 


$$
\begin{aligned}
& \mathcal{R}(F)=(\underbrace{\rho_{F}}_{\text {delivery }} \underbrace{-F}_{\text {removal }}) \Delta \Theta \underbrace{-k_{o n} F R_{f}+k_{\text {off }}^{F} C_{f}}_{\text {complex formation }} \underbrace{-\delta_{F} F}_{\text {decay }} \\
& \mathcal{R}(L)=(\underbrace{\rho_{L}}_{\text {delivery removal }} \underbrace{-L}_{\text {complex formation }}) \Delta \Theta \underbrace{-k_{o n} L R_{l}+k_{\text {off }}^{L} C_{l}}_{\text {decay }} \underbrace{-\delta_{L} L} \\
& \mathcal{R}(A)=(\underbrace{\rho_{A}\left(1+\sigma_{G}\right)}_{\text {production }} \underbrace{-A}_{\text {removal }}) \Delta \Theta \underbrace{-\delta_{A} A}_{\text {decay }} \underbrace{-\rho_{E} \Gamma \frac{A}{A+K_{M}} I\left(1+\sigma_{E} \sigma_{G}\right)\left(1+\sigma_{G}\right)}_{\text {catalysis into estradiol }} \\
& \mathcal{R}(E)=\underbrace{-E}_{\text {removal }} \Delta \Theta \underbrace{-k_{o n} E R_{e}+k_{o f f}^{E} C_{e}}_{\text {complex formation }} \underbrace{-\delta_{E} E}_{\text {decay }} \underbrace{+\rho_{E} \Gamma \frac{A}{A+K_{M}} I\left(1+\sigma_{E} \sigma_{G}\right)\left(1+\sigma_{G}\right)}_{\text {catalytic production }} \\
& \mathcal{R}\left(R_{f}\right)=\underbrace{\rho_{R_{f}}\left(\Gamma \vartheta+\sigma_{I}\left(1+\sigma_{E}\right)\right)}_{\text {production }} \underbrace{-k_{o n} F R_{f}+k_{o f f}^{F} C_{f}}_{\text {complex formation }} \underbrace{-\delta_{R} R_{f}}_{\text {decay }} \\
& \mathcal{R}\left(R_{l}\right)=\underbrace{\rho_{R_{l}} \sigma_{I}\left(1+\sigma_{E}\right)}_{\text {production }} \underbrace{-k_{o n} L R_{l}+k_{o f f}^{L} C_{l}}_{\text {complex formation }}-\underbrace{\delta_{R} R_{l}}_{\text {decay }} \\
& \mathcal{R}\left(R_{e}\right)=\underbrace{\rho_{R_{e}}\left(1+\sigma_{E}\right)\left(1-\sigma_{I 1}\right)}_{\text {production }} \underbrace{-k_{\text {on }} E R_{e}+k_{\text {off }}^{E} C_{e}}_{\text {complex formation }} \underbrace{-\delta_{R} R_{e}}_{\text {decay }} \\
& \mathcal{R}\left(C_{f}\right)=\underbrace{k_{\text {on }} F R_{f}-k_{\text {off }}^{F} C_{f}}_{\text {complex formation }} \underbrace{-\delta_{C F} C_{f}}_{\text {decay }} \\
& \mathcal{R}\left(C_{l}\right)=\underbrace{k_{\text {on }} L R_{l}-k_{\text {off }}^{L} C_{l}}_{\text {complex formation }} \underbrace{-\delta_{C L} C_{l}}_{\text {decay }} \\
& \mathcal{R}\left(C_{e}\right)=\underbrace{k_{\text {on }} E R_{e}-k_{\text {off }}^{E} C_{e}}_{\text {complex formation }} \underbrace{-\delta_{C E} C_{e}}_{\text {decay }} \\
& \mathcal{R}(I)=\underbrace{\rho_{I} \sigma_{G}}_{\text {production decay }} \underbrace{-\delta_{I} I}
\end{aligned}
$$

We use zero flux boundary conditions for all hormones, receptors and their complexes, i.e.

$$
\nabla c_{i}=0 .
$$

As initial conditions we use zero for the hormones, receptors and hormone-receptor complexes, because we intend to study the mechanisms that result in the emergence of the characteristic gene expression patterns in the follicle, i.e.

$$
\begin{aligned}
F(0) & =L(0)=E(0)=A(0)=0 \\
R_{F}(0) & =R_{L}(0)=R_{E}(0)=0 \\
C_{F}(0) & =C_{L}(0)=C_{E}(0)=0 .
\end{aligned}
$$


The only exception is the initial concentration of the IGF-receptor complex. IGF-2 and the IGF type receptor are expressed in the theca already at the time of antrum formation [60], and the early presence of the IGF-receptor complex in the theca is important in the model to reproduce the experimentally observed early expression of $\mathrm{LH}$ receptors in the theca $[15,16]$. To reproduce the measured $\mathrm{LH}$ receptor production rate in the follicle at day 0 as reproduced in Figure 3A we require

$$
I(0)=0.3 K_{I} \Theta .
$$

where $\Theta$ indicates the restriction to the theca and $K_{I}$ is the Hill constant for IGF-dependent regulatory processes.

\section{Detailed derivation of the reaction terms}

In the following we discuss how the reaction terms in Eqs. 6-16 were derived from the results reported in the literature.

Exchange with the blood FSH, LH, and steroid precursors are all produced outside the ovary and reach the theca via the blood, while estradiol is produced within the ovary and diffuses out off the ovary into the blood circulation [12]. The exchange with the blood results in a concentration flux in the theca. We describe this by including a constant source term for FSH, LH, and the androgen precursor in the theca, as well as a linear loss term for all soluble components (i.e. FSH, LH, androgens and estradiol) also in the theca. The exchange with the blood occurs at a rate $\Delta$. Accordingly, the FSH, LH, and androgen delivery rates, $\rho_{F}, \rho_{L}$, and $\rho_{A}$ are multiplied by $\Delta \Theta$ (Eq. 3), i.e we have $\rho_{F} \Theta \Delta, \rho_{L} \Theta \Delta$, and $\rho_{A} \Theta \Delta$ in Eqs. 6-8. The delivery from the blood is balanced by a removal rate $\Theta \Delta c_{i}$, that applies to all soluble components, i.e. $c_{i}=\{F, L, E, A\}$.

Decay, internalization and recycling In the absence of contrary data we use the simplest model for decay, linear decay at rate $\delta_{i} c_{i}$, where $\delta_{i}$ refers to the linear decay rate constant for component $i$. Internalized FSH and LH receptors do not recycle to the cell surface [42]. Potential recycling of estrogen receptors can be absorbed in the estradiol production rate, in particular because estrogen receptor signalling enhances estrogen receptor expression. To keep the model simple we thus do not include an independent term for estrogen receptor recycling.

Binding reactions $\mathrm{FSH}, \mathrm{LH}$, and Estradiol all bind their respective receptors at rate $k_{o n}$ and unbind with a specific rate $k_{o f f}^{i}$, where $i=\{F, L, E\}$.

Regulatory interactions The regulatory network is complex with many incoherent feedbacks and indirect regulatory interactions. Thus, production of FSH, LH and estrogen receptor are all enhanced by FSH, LH, and estradiol signalling [61-64]. However, many of these effects will reflect the multiple feedbacks between these components rather than direct auto-activation. These regulatory interactions can be at least in part be entangled with the help of mutant phenotypes and cell culture experiments. Thus, if expression of a gene is still observed in a certain mutant, then it is clear that this factor is not strictly necessary for the expression of the gene, but just enhances its expression. In that case the rate is proportional to $1+f\left(c_{i}\right)$, where $f(\cdot)$ denotes the particular functional relationship of the regulation and the +1 term enables the independent regulation of gene expression by other factors. Likewise if expression of a gene is observed only with a long delay after exposure to a certain factor it is likely that this factor does not act directly, but first up-regulates other factors that drive expression of the gene of interest. Such delays are important and need to be incorporated by introducing the intermediary factor.

Some of the processes are modulated by other signalling components and we use Hill functions to describe such regulatory influences. To describe activating influences of a component $c_{i}$ we write

$$
\sigma_{i}=\frac{c_{i}^{n_{i}}}{c_{i}^{n_{i}}+K_{i}^{n_{i}}} .
$$

and we use $1-\sigma_{i}$ to describe inhibitory impacts of $c_{i}$. Here $c_{i}$ denotes the concentration of component $i . K_{i}$ is the Hill constant which specifies the concentration of $c_{i}$ where half-maximal activity is observed, and the Hill coefficient $n_{i}$ defines the steepness of the response.

In the following we will discuss the reported evidence and how this was translated into the production terms.

FSH AND LH SIGNALING: Both the LH- and FSHreceptors are rhodopsin-like G-protein coupled receptors with great sequence identity [65] and connect to the same signalling machinery [66-69]. It is therefore possible that the observed differences in signalling outcomes mainly reflect ligand availability rather than distinct signalling programs by the receptor. We follow and test this possibility by making all regulatory impacts that have been reported for either LH or FSH signalling depended on both, i.e. instead of writing either $\sigma_{F}$ or $\sigma_{L}$ we will always write $\sigma_{G}=\sigma_{F}+\sigma_{L}$.

IGF SIGNALING: The regulation of IGF signalling is complex with several ligands, receptors, and modulating binding proteins and proteases being part of the regulatory network. In follicles only expression of IGF-2 but not that of IGF-1 is detected, and expression of IGF-2 is restricted to the theca $[60,70]$. The level of IGF-2 expression seems not to change much during follicular development [60]. Type 1 IGF receptor mRNA 


\begin{tabular}{|c|c|c|c|c|}
\hline & Parameter & Simulation value & Reference value & References \\
\hline & $\Lambda(0)$ & $5 \mathrm{~mm}$ & $4-5 \mathrm{~mm}$ & [20] \\
\hline & $v$ & $2.3 \times 10^{-5} \mathrm{~mm} \mathrm{~s}^{-1}$ & $\sim 10 \mathrm{~mm}$ in 5 days & [20] \\
\hline & $D_{H}$ & $6.7 \times 10^{-5} \mathrm{~mm}^{2} \mathrm{~s}^{-1}$ & Average $6.7 \times 10^{-5} \mathrm{~mm}^{2} \mathrm{~s}^{-1}$ for FSH & {$[21,22]$} \\
\hline & $D_{S}$ & $10^{-4} \mathrm{~mm}^{2} \mathrm{~s}^{-1}$ & Small molecule Diff coeff $10^{-4} \mathrm{~mm}^{2} \mathrm{~s}^{-1}$ & {$[23,24]$} \\
\hline & $D_{C_{L}}$ & $2 \times 10^{-8} \mathrm{~mm}^{2} \mathrm{~s}^{-1}$ & $1.9 \pm 1 \times 10^{-8} \mathrm{~mm}^{2} \mathrm{~s}^{-1}$ & [25] \\
\hline & $D_{R}$ & $10^{-7} \mathrm{~mm}^{2} \mathrm{~s}^{-1}$ & $10^{-9}-5 \times 10^{-7} \mathrm{~mm}^{2} \mathrm{~s}^{-1}$ & [26-29] \\
\hline & $D_{1}$ & $4 \times 10^{-9} \mathrm{~mm}^{2} \mathrm{~s}^{-1}$ & IGF receptor complex almost immobile & [26] \\
\hline & $k_{\text {on }}$ & $10^{-3} \mathrm{nM}^{-1} \mathrm{~s}^{-1}$ & Standard value & [30] \\
\hline & $k_{o f f}^{F}$ & $5 \times 10^{-4} s^{-1}$ & Average: $K_{D}=5 \times 10^{-10} \mathrm{M}^{-1}$ & [31-36] \\
\hline & $k_{\text {off }}^{L}$ & $10^{-2} s^{-1}$ & $K_{D}=9 \mathrm{nM}$ & [37] \\
\hline Parameter values & $k_{\text {off }}^{E}$ & $10^{-4} s^{-1}$ & $K_{D}=0.1 \mathrm{nM}$ & [38] \\
\hline directly from & $\delta_{F}$ & $10^{-5} s^{-1}$ & Half-life of FSH in ovariectomized ewes is $20 \mathrm{~h}$ & [39] \\
\hline \multirow[t]{11}{*}{ the literature } & $\delta_{L}$ & $5 \times 10^{-4} s^{-1}$ & Half-life of LH in ovariectomized rats is 23 minutes & {$[40]$} \\
\hline & $\delta_{R_{F}}=\delta_{R_{L}}$ & $3 \times 10^{-5} s^{-1}$ & Measured decay rate $3 \times 10^{-5} \mathrm{~s}^{-1}$ & [41] \\
\hline & $\delta_{C_{L}}$ & $7.5 \times 10^{-4} s^{-1}$ & Half-life LH/hCG-bound receptor 17 min & {$[40-42]$,} \\
\hline & $\delta_{C_{F}}=\delta_{C_{E}}=\delta_{E}=\delta_{A}$ & $6.4 \times 10^{-5} \mathrm{~s}^{-1}$ & Half-life is about 3 hours & {$[39,43-46]$} \\
\hline & $\delta_{l}$ & $1.2 \times 10^{-6} \mathrm{~s}^{-1}$ & Half-life $\sim 10$ hours & [47-49] \\
\hline & $\rho_{R_{F}}=\rho_{R_{L}}$ & $500 \times 0.5 \mathrm{pM} \mathrm{s}^{-1}$ & $21 \mathrm{receptors} / \mathrm{cell} / \mathrm{min}=500 \times 0.5 \mathrm{pM} \mathrm{s}^{-1}$ & {$[7,41,50-52]$} \\
\hline & $\rho_{E}$ & $0.06 s^{-1}$ & $k_{\text {cat }}=0.06 \mathrm{~s}^{-1}$ & {$[53,54]$} \\
\hline & $K_{M}$ & $44 \mathrm{nM}$ & $K_{M}=44 \mathrm{nM}$ & {$[53,54]$} \\
\hline & $\rho_{F}$ & $2 \mathrm{nM}$ & FSH concentration $\sim 2 \mathrm{nM}$, flux $\Delta=1 \mathrm{~s}^{-1}$ & [55] \\
\hline & $\rho_{L}$ & $0.4 \rho_{F}$ & LH concentration $40 \%$ of that of FSH & [56] \\
\hline & $\rho_{R_{E}}$ & $1.25 \mathrm{pM} \mathrm{s}^{-1}$ & 45000 estrogen receptors are detected per cell & [57] \\
\hline \multirow{3}{*}{ Adapted } & $\rho_{l}$ & $2.8 K_{l} \delta_{l}$ & Reproduce measured granulosa LH receptor numbers ( $\leq 3 \mathrm{nM})$ & [7] \\
\hline & $\rho_{A}$ & $100 \mathrm{nM}$ & Reproduce androgen concentration in follicular fluid & {$[55,58]$} \\
\hline & $K_{1}$ & $5 \mu \mathrm{M}$ & Reproduce estradiol concentration in follicular fluid & {$[55,58]$} \\
\hline
\end{tabular}


Table 1 Parameter values(Continued)

\begin{tabular}{lccc}
\hline & $K_{L}$ & $500 \times 10 \mathrm{pM}$ & Reproduce steepness of expression kinetics in Figure 3A \\
& $K_{F}$ & $500 \times 3 \mathrm{nM}$ & Reproduce steepness of expression kinetics in Figure 3B \\
Figure 3 & $K_{E}$ & $35 \mathrm{nM}$ & Reproduce steepness of expression kinetics in Figure 3B \\
& $\vartheta$ & 0.2 & Reproduce ordinate intercept in Figure 3C \\
\cline { 2 - 4 } & $I(0)$ & $0.3 K_{l} \Theta$ & Reproduce ordinate intercept in Figure 3A \\
\hline
\end{tabular}

The table summarizes all parameter values used in the model along with the evidence. For details see the Parameter Section. In addition to the listed parameters we used $F(0)=L(0)=E(0)=A(0)=R_{i}(0)=C_{i}(0)=0$ as

initial conditions, $\Delta=1 \mathrm{~s}^{-1}$ as exchange rate with the blood, and $n=2$ as Hill coefficient. It should be noted that the factor 500 for the FSH and LH receptor production rates and Hill constants reflects the smaller membrane compartment $\left(\sim 2.5 \mu \mathrm{m}^{3}\right)$ compared to the entire cell (1140 $\mu \mathrm{m}^{3}[59]$ ). 
is detected in both granulosa and theca cells of preantral and antral follicles, but expression is stronger in granulosa compared to the theca [60]. The circulating IGF concentration in healthy adults is $\sim 100 \mathrm{nM}$ and the IGF type I receptor on most cells is typically approaching saturation at a concentrations of $5 \mathrm{nM}$ or lower [71]. It has therefore been suggested that IGF activity is mainly regulated through IGF binding proteins (IGFBP), which sequester IGF in inactive complexes rather than through differences in the secretion of IGF. The IGFBP4 mRNA is selectively expressed by LH receptor (LHR) mRNA positive theca interna cells of healthy antral follicles (defined by aromatase and gonadotropin receptor expression) and by LHR expressing granulosa cells, which are present in large preovulatory and ovulatory follicles only (as defined by size and aromatase expression) [70]. In the mouse and the rat FSH stimulates the expression of PAPP-A, a metalloprotease which degrades IGF-B4 [72]. However, no such an effect was observed in bovine follicles [73]. The PAPP-A mRNA is abundant in granulosa cells of most ovarian follicles without obvious relation to IGFBP4 expression [70]. IGFBP4 mRNA levels are markedly increased after treatment with the LH ana$\log$, human chorionic gonadotropin ( $\mathrm{hCG}$ ), whereas the expression levels of IGF-2 and PAPP-A are not significantly altered [70]. In summary, there is evidence only for IGFBP4 being (positively) regulated by $\mathrm{LH}$, while all other components appear to be expressed at a constant level. Since IGF-2 is expressed only in the theca, IGF signalling in the granulosa must be the result of diffusion. The diffusion coefficient of IGF-1 in cartilage has been established as $D=2.6 \times 10^{-5} \mathrm{~mm}^{2} \mathrm{~s}^{-1}$. The diffusion length is determined also by the rate of ligand removal, by either receptor binding or unspecific degradation; the half-life of circulating unbound IGF has been found to be less than 2 min [74]. The characteristic length of such a gradient would be very short, i.e $\lambda=\sqrt{\frac{D}{k}} \leq 70 \mu \mathrm{m}$. The IGF binding proteins protect IGF from receptor binding and can thereby help to shuttle IGF into the follicle. The half-life in the presence of IGF binding proteins is increased some 100 -fold by IGF binding proteins to several hundreds minutes, and as a result the gradient will some 10-fold wider. Thus, even though IGF binding proteins sequester IGF and remove it from the available active pool they also enable its transport into the follicle. Instead of simulating all those aspects in detail, we simplify the regulatory interactions in that we follow only the concentration of the active IGF-receptor complex which we denote be $I$.

Production and catalytic conversions IGF RECEPTOR COMPLEX PRODUCTION: The concentration of the active IGF complex is enhanced by FSH and LH signalling $[60,72,75]$, and accordingly we write for the rate of its generation $\rho_{I} \sigma_{G}$ in Eq. 16. Estradiol has been shown to both enhance and decrease IGF-1 expression in different experimental systems $[76,77]$ and its effects will therefore not be included here.

LH RECEPTOR PRODUCTION: FSH and LH signalling results in the expression of a protein that limits the half-life of their mRNAs [78-80], such that FSH and LH receptors can only transiently (i.e. for a few hours) up-regulate their expression $[63,64]$. Thus, LH-dependent induction of increased $\mathrm{LH}$ receptor density is present after $2 \mathrm{~h}$, but vanishes after $6 \mathrm{~h}[81]$. We will ignore this brief spike of auto-regulation and assume that there is no direct auto-regulation of FSH and $\mathrm{LH}$ receptor on their own expression on the relevant time scale (i.e. days). FSHdependent $\mathrm{LH}$ receptor expression is enhanced by estradiol signalling, and $\mathrm{LH}$ receptor expression is reduced (but not absent) in response to the FSH analog in estrogen receptor-null follicles [82]. The rate of LH receptor expression must thus be proportional to $\left(1+\sigma_{E}\right)$. FSHdependent $\mathrm{LH}$ receptor expression cannot be triggered by estradiol in the absence of FSH $[16,63]$ and the expression rate must therefore directly be dependent on an FSHdependent term. FSH-dependent LH receptor expression is delayed $[7,15,16]$. Thus, stimulation with FSH increased the LH receptor density 10 -fold within two days, with little change observed after 1 day [7]. FSH thus appears to act indirectly, possibly via IGF $(I)$ or prolactin signalling [81]. IGF signalling is included explicitly in the model and any possible effects of other signalling systems such as prolactin can be considered to be implicitly represented by this variable. The delayed impact of FSH-dependent signalling of LH receptor expression can then be captured by making the $\mathrm{LH}$ receptor expression rate proportional to $\sigma_{I}\left(1+\sigma_{E}\right)$. FSH-dependent IGF-1 and LH receptor production is inhibited in cumulus cells by factors secreted by the oocyte $[83,84]$ and $\mathrm{LH}$ receptor expression has been reported to be virtually absent in cumulus cells [83]. However, more recent experiments that use more sensitive techniques revealed the expression of the $\mathrm{LH}$ receptor in cumulus cells $[19,85]$. We therefore permit LH receptor expression throughout the follicle. In summary, we have $\rho_{R_{l}} \sigma_{I}\left(1+\sigma_{E}\right)$ for the $\mathrm{LH}$ receptor production rate in Eq. 11 .

FSH RECEPTOR PRODUCTION: As discussed above, FSH and LH signalling results in the expression of a protein that limits the half-life of their mRNAs [78-80], such that FSH and $\mathrm{LH}$ receptors can only transiently (i.e. for a few hours) up-regulate their expression [63,64]. Also in case of FSH receptor we will ignore this brief spike of auto-regulation and assume that there is no direct auto-regulation of FSH and $\mathrm{LH}$ receptor on their own expression on the relevant time scale (i.e. days). Similar as for the LH receptor IGF signalling has been shown to prolong the half-lifes of the FSH receptor mRNAs $[72,86]$. 
The IGF effect is observed only after a delay, i.e. IGF has been described to enhance FSH-dependent FSH receptor expression on rat granulosa cells after about 3 days of exposure [72] as is consistent with its delayed induction in granulosa cells. Also much as in case of the LH receptor, estradiol enhances FSH receptor expression on rat granulosa cells [87]. Thus, similar as for the LH receptor, the rate of FSH receptor expression should be $\rho_{R_{f}} \sigma_{I}\left(1+\sigma_{E}\right)$. Unlike for the LH receptor, FSH-dependent FSH receptor expression is strongly reduced in IGF-null granulosa cells, but not absent [88], and FSH receptor expression in response to $\mathrm{FSH}$ or $\mathrm{LH}$ analogs was not impaired in estrogen receptor-null follicles [82]. There must therefore also be a FSH/LH/estrogen-independent regulation of FSH receptor expression, possibly triggered by testosterone signalling which has been described to induce the expression of FSH receptor and of aromatase [89]. The testosterone receptor is restricted to granulosa cells [90] and given the high steroid concentrations within the follicle the ligand-receptor complex can be assumed to have a constant activity $\vartheta$. Here we ignore any possible feedback signalling that may up-regulate the expression of the receptor. In summary, we write for the FSH receptor expression rate $\rho_{R_{f}}\left(\Gamma \vartheta+\sigma_{I}\left(1+\sigma_{E}\right)\right)$ in Eq. 10.

ESTROGEN RECEPTOR PRODUCTION: In the mouse estrogen receptor beta is the main form expressed in the follicles and is found mainly in granulosa cells, but has also been detected in the theca $[82,91]$. In bovine and sheep follicles both estrogen receptor alpha and beta are expressed in the granulosa and to a lesser extent in the theca $[92,93]$. In humans mainly estrogen receptor beta is detected in the granulosa cells, but also low levels of estrogen receptor alpha expression has been detected [94]. Estrogen receptor beta expression is enhanced by estradiol signalling and the production rate should therefore be proportional to $\left(1+\sigma_{E}\right)$ [61,95]. There are also reports that FSH signalling inhibits estrogen receptor beta expression $[61,95]$. Since estrogen receptor beta is expressed mainly in granulosa cells FSH signalling may act indirectly via IGF signalling which is prominent in the theca; IGF receptor signalling has been shown to reduce estrogen receptor beta expression [96]. Accordingly, the estrogen receptor expression rate needs to be extended to $\left(1+\sigma_{E}\right)\left(1-\sigma_{I}\right)$ to include this inhibitory effect. While LH-dependent signalling appears to interfere with IGF activity by inducing the expression of IGFBP4 mRNA [70] this additional feedback will be ignored to keep the model as simple as possible. In summary, we have $\rho_{R_{e}}\left(1+\sigma_{E}\right)\left(1-\sigma_{I 1}\right)$ for the estrogen receptor production rate in Eq. 12.

ANDROGEN PRODUCTION: LH receptor signalling enhances the production of androgens in the theca [15], but only $25-50 \%$ of androgens is produced in the ovary (varying through the menstrual cycle) [53]. We therefore write for the androgen production term $\rho_{A} \Theta\left(1+\sigma_{G}\right)$ in Eq. 8. It should be noted that despite the inclusion of FSH signalling, FSH will impact very little on androgen production because of the very low abundance of FSH receptors in the theca. It should be noted that high concentrations of LH appear to inhibit androgen production [97], but we ignore this to keep the model as simple as possible while reproducing the data.

ESTRADIOL PRODUCTION: Aromatase converts androgens into estradiol [98]. No feedback activity involving aromatase has been reported. To keep the model as simple as possible we therefore do not explicitly include the aromatase in the model, but rather incorporate the regulatory links that impact on its activity. Both the expression and the activity of aromatase are enhanced by FSH and LH signalling in the granulosa cells $[7,98,99]$. Estrogen receptor signalling enhances FSH-dependent expression of aromatase [82], and IGF signalling is necessary for FSH-dependent expression of aromatase $[88,100]$ and enhances FSH-dependent estradiol production [101]. Testosterone signalling has been described to induce the expression of FSH receptor and of aromatase [89]. There is thus also some FSH/IGF-independent expression of aromatase. However, since based on data (Figure 3D) the effect is small we ignore this contribution and take the aromatase expression rate to be proportional to $I\left(1+\sigma_{E} \sigma_{G}\right)$. The activity of the aromatase is enhanced by FSH and should therefore be proportional to $I(1+$ $\left.\sigma_{E} \sigma_{G}\right)\left(1+\sigma_{G}\right)$. Accordingly, we then have according to the Michaelis-Menten law for the estradiol production rate in Eq. 9, $\rho_{E} \Gamma \frac{A}{A+K_{M}} I\left(1+\sigma_{E} \sigma_{G}\right)\left(1+\sigma_{G}\right)$, where $K_{M}$ is the Michaelis-Menten constant; $\Gamma$ indicates the restriction of the aromatase to granulosa and cumulus cells [102]. FSH and LH-dependent responses have been shown to be concentration-dependent: low concentrations of FSH and LH act stimulatory while high concentrations have negative impact on steroid production [97]. To keep the model as simple as possible while reproducing the data we will not include this feedback here; it would likely increase robustness to parameter value changes.

\section{Parameters}

In spite of the large number of parameters, the model is rather tightly constrained because an enormous amount of data from cows and other animals is available that determine the parameter values. Where possible we use the measurements from cows. Table 1 summarizes all parameter values used in the model along with the evidence. The first 28 parameter values have been directly measured in experiments, 4 further values can be directly inferred from information in the literature, and the remaining 4 were set to fit the data in Figure 3, as was the initial condition $I(0)$. In addition to the parameters listed above we used 
$F(0)=L(0)=E(0)=A(0)=R_{i}(0)=C_{i}(0)=0$ as initial conditions to study the emergence of pattern from zero initial conditions. Furthermore, the exchange with the blood is modelled by a constant exchange rate, $\Delta$. The exchange rate with the blood is not known, but as long as $\Delta \geq 1 \mathrm{~s}^{-1}$ the flux does not impact on the predicted expression patterns in the follicle; we use $\Delta=1 \mathrm{~s}^{-1}$. Finally the Hill coefficient in the regulatory terms was set to $n=2$ throughout as in our previous models of developmental signalling networks [103-105]. In the following we discuss the literature on the parameter values in detail.

\section{Length and time scales}

In both humans and cattle 2-3 waves of follicle maturation occur until the dominant follicle survives and becomes ovulated $[20,106]$. We simulate the first wave of bovine folliculogenesis and focus on the FSH-dependent developmental phase of the dominant follicle, which lasts about 4-6 days before the dominant follicle of the first wave undergoes atresia [20]. The final day of the first wave is already characterized by atresia of the dominant follicle [16], and accordingly we include only the gene expression data of the first four days in Figure 3. The follicle is initially $5 \mathrm{~mm}$ in diameter and expands over 4-6 days to $15-20 \mathrm{~mm}$ [20]. Based on the experimental observation that the follicle grows by about $10 \mathrm{~mm}$ in 5 days we use $L(0)=5 \mathrm{~mm}$ and $v=2.3 \times 10^{-5} \mathrm{~mm} \mathrm{~s}^{-1}$.

\section{Diffusion coefficients}

The diffusion constant of FSH has been determined as $6 \times 10^{-5} \mathrm{~mm}^{2} \mathrm{~s}^{-1}$ for sheep FSH [21] and $7.43 \times 10^{-5}$ $\mathrm{mm}^{2} \mathrm{~s}^{-1}$ for porcine FSH [22]. Accordingly, we will use the average of $6.7 \times 10^{-5} \mathrm{~mm}^{2} \mathrm{~s}^{-1}$ as FSH diffusion coefficient. Given the great similarity of FSH and LH the same diffusion coefficient will also be used for LH. Steroids are very small and their diffusion coefficient is therefore set to $D_{S}=10^{-4} \mathrm{~mm}^{2} \mathrm{~s}^{-1}$, a typical value for small, diffusable compounds in aqueous solutions [23,24]. The diffusion coefficient of the LH-bound receptor complex has been established as $1.9 \pm 1.0 \times 10^{-8} \mathrm{~mm}^{2} \mathrm{~s}^{-1}$ [25]. Interestingly, the diffusion coefficient of hCG-bound receptor complex was less than $10^{-9} \mathrm{~mm}^{2} \mathrm{~s}^{-1}$. Deglycosylated hCG-bound receptor complexes had a similar diffusion coefficient as $\mathrm{LH}$-bound receptor complexes and were internalized also at the 50-times faster rate that is characteristic for $\mathrm{LH}$ bound receptors. Accordingly. we have $D_{C_{L}}=2 \times 10^{-8}$ $\mathrm{mm}^{2} \mathrm{~s}^{-1}$, which is more than 1000 -fold lower than the diffusion coefficient for the ligand. The diffusion coefficient of the insulin receptors has been established as $(3-5) \times$ $10^{-8} \mathrm{~mm}^{2} \mathrm{~s}^{-1}$ at 23 degree Celsius [26]. Increasing the temperature to 37 degrees Celsius resulted in rapid receptor immobilization; the immobilization was attributed to aggregation of hormone-receptor complexes, their internalization, or a combination of both processes [26]. For simplicity we did not consider the unbound and bound IGF receptors separately in the model. To account for this we do not set the diffusion coefficient for the IGF receptor complex to zero, but to a 10 -fold lower value than measured at 23 degree Celsius, i.e. $D_{I}=4 \times 10^{-9} \mathrm{~mm}^{2} \mathrm{~s}^{-1}$. The diffusion coefficient of the FSH receptor has been measured as $4.4 \times 10^{-5} \mathrm{~mm}^{2} \mathrm{~s}^{-1}$ [107], which is unusually similar to that of the soluble protein, but at the upper end of what has been measured for membrane receptors [27-29]; the typical diffusion coefficient for unhindered diffusion in the membrane is about $10^{-7} \mathrm{~mm}^{2} \mathrm{~s}^{-1}$ [27$29,108]$. Since diffusion of the FSH receptors, much as diffusion of the cytoplasmic estrogen receptors will be restricted by the cell boundaries, even if cellular diffusion was very fast, we will use $D_{R}=10^{-7} \mathrm{~mm}^{2} \mathrm{~s}^{-1}$, the diffusion coefficient for unhindered membrane diffusion [27-29,108], for all other receptors. The use of a continuum description is reasonable in spite of the spatially restricted diffusion due to cell boundaries the diffusion coefficient is sufficiently low such that the cell-restricted proteins diffuse less than a cell diameter $(\sim 7-10 \mu \mathrm{m})$ within their half-life as discussed in detail before [104].

\section{Binding rates}

To avoid numerical problems we formulated our model for nanomolar concentrations rather than the SI standard of molar concentrations. The on-rates $k_{\text {on }}$ are then $10^{-3} \mathrm{nM}^{-1} s^{-1}$ [30]. The affinity constants for the ligandreceptor interactions have been independently determined in a range of different species and tissues and the reported values are very similar. The affinity constant for the FSH-receptor interaction has been determined as $K_{a}=1.5 \pm 0.3 \times 10^{9} M^{-1}\left(K_{d}=6.7 \times 10^{-10} M^{-1}\right)[31]$ and $K_{d}=9.8 \times 10^{-11} M^{-1}$ [32] in bull testes, as $K_{d}=6.7 \times$ $10^{-10} M^{-1}$ in rat testes [33], and $K_{d}=9.4 \times 10^{-10} M^{-1}$ [34], $K_{a}=3 \times 10^{9} M^{-1}\left(K_{d}=3.4 \times 10^{-10} M^{-1}\right)$ [35], and $K_{d}=1.5 \times 10^{-10} M^{-1}$ [36] for the human FSH receptor. The average measured $K_{d}=5 \times 10^{-10} M^{-1}$ corresponds to an off-rate $k_{\text {off }}^{F}=5 \times 10^{-4} \mathrm{~s}^{-1}$. Human LH binds the rat $\mathrm{LH}$ receptor with $K_{D}=0.09 \mathrm{nM}$ and the human $\mathrm{LH}$ receptor with a 100-fold lower affinity, $K_{D}=9 \mathrm{nM}$ [37]. hCG binds the human LH receptor with a similar affinity, i.e. $K_{D}=4 \mathrm{nM}$ [37]. Accordingly, we use $k_{\text {off }}^{L}=10^{-2} \mathrm{~s}^{-1}$. Estradiol binds its receptor with $K_{D} \sim 0.1 \mathrm{nM}$ [38] which corresponds to $k_{o f f}^{E}=10^{-4} \mathrm{~s}^{-1}$. It should be noted that affinities and half-lifes have been reported to vary due to different glycosylations [56], but such details are beyond the scope of this study.

\section{Decay and removal rates}

The half-life of LH has been determined in ovary-intact rats as $13.7 \pm 0.7 \mathrm{~min}$ [40]. The half-life increases to $23.1 \pm$ $2.9 \mathrm{~min}$ in ovariectomized rats [40]. While the degradation of $\mathrm{LH}$ in the ovariectomized rats will also reflect 
receptor-dependent degradation in other organs, 23 min must represent the lower limit for the receptorindependent half-life for $\mathrm{LH}$ (i.e. $\delta_{L} \leq 5 \times 10^{-4} \mathrm{~s}^{-1}$ ). The half-life of $\mathrm{LH}$ in ovary-intact rats of 14 minutes $\left(\delta_{C_{L}}=8 \times 10^{-4} \mathrm{~s}^{-1}\right)$ is similar to the measured halflife of the hCG-stimulated human LH receptor of $17 \mathrm{~min}$ [42], and corresponds well to the decay rate of LH-bound LHR in MA-10 strains, a clonal strain of mouse Leydig tumour cells, which is $7 \times 10^{-4} \mathrm{~s}^{-1}$ [41]. In summary we will use the average rate $\delta_{C_{L}}=7.5 \times 10^{-4} \mathrm{~s}^{-1}$ for the receptor-dependent rate of LH clearance. The turnover rate for unbound $\mathrm{LH}$ receptor has been determined as $\delta_{R_{L}}=3 \times 10^{-5} \mathrm{~s}^{-1}$, and the intracellular degradation rate is $9 \times 10^{-5} \mathrm{~s}^{-1}$ [41].

The half-life of FSH is about $3 \mathrm{~h}$ in ovary-intact ewes and about 20 hours in ovariectomized ewes [39]. While the degradation of FSH in the ovariectomized ewes will also reflect receptor-dependent degradation in other organs, 20 hours represents the lower limit for the receptorindependent half-life for $\mathrm{FSH}$, and we use $\delta_{F} \sim 10^{-5}$ $\mathrm{s}^{-1}$. The receptor-dependent half-life of 3 h corresponds to $\delta_{C f}=6.4 \times 10^{-5} \mathrm{~s}^{-1}$. Given the great similarity of the $\mathrm{LH}$ and the FSH receptor we use the same ligand-independent turnover rate, i.e. $\delta_{R_{F}}=\delta_{R_{L}}=3 \times 10^{-5} \mathrm{~s}^{-1}$.

The half-life of androgens and estradiol has been reported as 2-3 $\mathrm{h}$ [43-45]. The half-life of the estrogen receptor-alpha protein has been reported as $3 \mathrm{~h}$ in the absence of estrogen, and as $1 \mathrm{~h}$ upon addition of the hormone [46]. ERa half-life subsequently increases over time, achieving a half-life of $\sim 6 \mathrm{~h}$ in $72 \mathrm{~h}$ of estrogen treatment [46]. In summary we use, similar as for the FSH receptor complex, $3 \mathrm{~h}$ as half-life for the steroid components, i.e. $\delta_{A}=\delta_{E}=\delta_{R_{E}}=\delta_{C_{E}}=\delta_{C_{F}}=6.4 \times 10^{-5} \mathrm{~s}^{-1}$.

The half-life of overexpressed IGF receptor complexes has been measured to be much larger than 6 hours and smaller than 16 hours [47], which would correspond to a decay rate of about $2 \times 10^{-5} \mathrm{~s}^{-1}$. In a subsequent study the same group reported a decay rate of $8 \times 10^{-5} \mathrm{~s}^{-1}$ using cells that expressed $10^{5}-10^{6}$ receptors per cell [48]. Granulosa cells have been reported to express $1125 \pm 382$ receptors per cell [109]. The rate of internalization was further reported to slow down substantially as insulin receptors become saturated, and half-maximal inhibition was observed already at $0.1 \mathrm{nM}$ insulin concentrations; addition of $100 \mathrm{nM}$ insulin reduced the internalization rate to less than $10 \%[48,49]$. Based on these in vitro data the IGF receptor turnover rate in granulosa cells is difficult to estimate, but it is likely to be substantially lower than the measured $2-8 \times 10^{-5} \mathrm{~s}^{-1}$, and we will use $\delta_{I}=1.2 \times 10^{-6} \mathrm{~s}^{-1}$.

Finally, the flux rate $\Delta$ determines the rate at which the soluble factors are delivered and removed from the follicle. This rate is not known. A low flux rate can lead to the removal and depletion of those soluble factors, which are delivered to the theca, i.e. FSH, LH, and the steroid precursor. A higher flux rate can in principle always be balanced by a higher production rate, but can cause numerical problems. To avoid such artefacts and problems we use as flux rate $\Delta=1 \mathrm{~s}^{-1}$.

\section{Production rates}

The bovine serum FSH concentration during the follicular phase has been established as $66 \mathrm{ng} / \mathrm{ml}$ in one study [110] and as $\sim 20 \mathrm{ng} / \mathrm{ml}$ in several others [55,111-113]. If we use $1 \mathrm{~g} \sim 1 \mathrm{ml}$ as done in similar studies before [114] and use $30 \mathrm{kDa}$ as the molecular weight of FSH we arrive at a serum concentration of 0.7-2 nM for FSH. We note that the reported bovine FSH concentration is somewhat lower than the reported concentration in humans. Human FSH and LH concentrations are typically reported as IU/l which can be converted into molar concentrations based on reported conversions into protein weight per liter. Thus, dependent on the hormone standard used 1 IU corresponds to about $46 \mu \mathrm{g}$ FSH or about $23 \mu \mathrm{g} \mathrm{LH}$ [115]. The molecular weight of both proteins is $30-35 \mathrm{kDa}$, depending on glycosylation. $1 \mathrm{IU} / \mathrm{l} \mathrm{FSH}$ then translates into about $1.5 \mathrm{nM}$, and $1 \mathrm{IU} / 1 \mathrm{LH}$ translates into about 0.75 $\mathrm{nM}$. FSH levels are high during the menstruation period (midcycle phase 4.5-22.5 IU/L) and lower in the middle of the cycle (follicular phase 3.9-8.8 IU/L and luteal phase 1.8-5.1 IU/L) [116,117]. In the human follicular phase the average FSH serum concentration has been reported as $5.3 \mathrm{IU} /$ liter $(8 \mathrm{nM})$ and the average $\mathrm{LH}$ concentration as 4.2 IU/liter (3.15 nM) [56]. In humans the serum LH concentration is thus about $40 \%$ that of $\mathrm{FSH}$. The bovine LH concentration was determined as $0.63 \mathrm{ng} / \mathrm{ml}$ per liter (and thus $20 \mathrm{pM}$ ) [55]. The low reported LH concentration in the bovine study may reflect the short half-life of only $14 \mathrm{~min}$ [40] which makes accurate measurements of the LH concentration more difficult. In fact, in ewes the $\mathrm{LH}$ concentration has been reported as $25 \mathrm{ng} / \mathrm{ml}-50$ $\mathrm{ng} / \mathrm{ml} \mathrm{LH} \mathrm{[118]} \mathrm{which} \mathrm{would} \mathrm{be} \mathrm{in} \mathrm{the} \mathrm{expected} \mathrm{range.}$ The reported LH concentration in the bovine follicular fluid ranges from 0.02 to $0.63 \mathrm{nM}[55,58]$ where the lower value was again reported by Rhind and co-workers. In conclusion, we suspect that the reported bovine LH serum concentration is underestimated. We therefore adjusted the production and loss rate in the theca such that the FSH concentration was $2 \mathrm{nM}$, the upper range of the reported bovine concentrations and the lower range of the reported human concentrations, i.e. $\rho_{F}=\Delta 2 \mathrm{nM}$, and the LH concentration to $40 \%$ of this, i.e. $\rho_{L}=0.4 \rho_{F}$. Oscillations in the dynamics of $\mathrm{LH}$ are ignored in this model. The impact of the LH/FSH concentration and ratio are explored in detail in the Results section.

The $\mathrm{LH}$ receptor production rate has been measured in a cell culture system as 21 receptors/cell/min [41] and the cell volume of human ovarian granulosa cells has been 
established as $1140 \mu \mathrm{m}^{3}$ [59]. This would then translate to $\rho_{R_{L}}=0.5 \mathrm{pM} \mathrm{s}^{-1}$. The LH and FSH receptors are plasma membrane receptors and their reaction volume is therefore much smaller, even though both the oocyte and granulosa cells have elaborate numerous cytoplasmic projections and microvilli that interdigitate with each other to create an extremely large surface area for diffusion. Thus, the surface area of granulosa cells has been established by scanning electron microscope as $198.5 \pm 6.3 \mu \mathrm{m}^{2}$ in unstimulated control rabbits and as $242.8 \pm 9.28 \mu \mathrm{m}^{2}$ in rabbits injected $12 \mathrm{~h}$ earlier with hCG [119]. The effective binding volume for the receptors would thus be much smaller, i.e. $250 \mu \mathrm{m}^{2} \times 0.01 \mu \mathrm{m}=2.5 \mu \mathrm{m}^{3}$ where we use a binding length of $10 \mathrm{~nm}$ as discussed elsewhere [120]. To take into account that the $\mathrm{LH}$ receptor is a membrane protein we thus need to use an about 500 -fold higher receptor production rate, i.e. $\rho_{R_{L}}=250 \mathrm{pM} \mathrm{s}^{-1}$ for the discrete receptor reaction volume. We note that while this number provides a better estimate for the effective binding kinetics, it greatly over-estimates the total amount of hormone that is removed, since we do not exclude the cell volumes (that are inaccessible to the hormones) from the simulations. Since the hormone concentration is kept constant in the theca this, however, does not affect any of our predictions. To include the effects of the membrane localisation of receptors a cell-based model would need to be devised.

The FSH receptor expression rate was set to that of the LH receptor, i.e. $\rho_{R_{F}}=\rho_{R_{L}}=250 \mathrm{pM} \mathrm{s}^{-1}$. The activity of the FSH/LH-independent regulation of FSH receptor expression was set to $\vartheta=0.2$ to reproduce the ordinate intercept in Figure 3C.

The simulated LH receptor concentration also depends on the concentration of IGF receptor complexes and thus on $\rho_{I}$. In cultured rat granulosa cells $200 \mathrm{LH}$ receptor sites were detected per cell [7] which corresponds to a concentration of about $300 \mathrm{pM}$ if we use $1140 \mu \mathrm{m}^{3}$ as granulosa cell volume [59] and $150 \mathrm{nM}$ if we use the much smaller reaction volume of $2.5 \mu \mathrm{m}^{3}$ as discussed above. Stimulation with FSH increased the LH receptor density 10-fold within two days, with little change observed after 1 day [7]. The maximal LH receptor concentration would thus be $3 \mathrm{nM}$ (or $1500 \mathrm{nM}$ if we use the much smaller reaction volume) in our model. To achieve such a concentration range in the model we require $\rho_{I}=2.8 K_{I} \delta_{I}$.

We have found measurements of the estrogen receptor concentration only in the pituary of ewes. In cell culture systems about 45000 estrogen receptors are detected per cell [57]. This would correspond to about $65 \mathrm{nM}$ and we therefore use $\rho_{R_{E}}=1.25 \mathrm{pM} \mathrm{s}^{-1}$. It should be noted that the much larger estrogen receptor concentration reflects its cytoplasmic/nuclear rather than membrane localisation. This much higher concentration, however, does not impact the model predictions as long as the Hill constant $K_{E}$ is adjusted accordingly.

Androgen production depends on the precursor concentration and on the stimulating impact of FSH and LH signalling. The most potent androgen, testosterone, is secreted by the adrenal zona fasciculata $(25 \%)$ and the ovarian stroma (25\%), with the remaining 50\% being produced from circulating andostrenedione [53]. Androstenedione is secreted by the adrenal zona fasciculata $(50 \%)$ and the ovarian stroma $(50 \%$, but varying through the menstrual cycle). The maximal follicular fluid concentrations of androstenoide and testosterone have been reported as $107 \mathrm{nM}$ and $100 \mathrm{nM}$ respectively [58]. Accordingly, we use as androgen production rate $\rho_{A}=$ $\Delta \times 100 \mathrm{nM}$, where $100 \mathrm{nM}$ would be the concentration of the precursors.

Estradiol is produced from androgens by the cytochrome P450 enzyme aromatase. The human cytochrome P450-dependent conversion rate, the rate limiting step in estrogen production, has been established as $k_{\text {cat }}=0.06 \mathrm{~s}^{-1} ; K_{M}=44 \mathrm{nM}$ [54]. Accordingly we use $\rho_{E}=0.06 \mathrm{~s}^{-1}$ and $K_{M}=44 \mathrm{nM}$.

\section{Hill constants and coefficients}

The Hill coefficient $n$ is not known, and much as in our previous studies of developmental signalling processes $[104,105]$ we will use $n=2$ throughout, which is in the likely physiological range [30] and which has the added benefit of rendering the simulation numerically more stable. Hill constants determine the concentration at which half the activity is attained. There are no direct measurements of the Hill constants, but these must lie within the dynamic range of the receptor-ligand complex concentration to enable the reported regulatory effect of the regulatory components. The Hill constant for the LH receptor determines the slope of the LH expression kinetics in Figure 3A and, to reproduce the data, needed to be set to $K_{L}=500 \times 10 \mathrm{pM}$ where the factor 500 reflects the smaller reaction volume of the membrane receptors as discussed in the previous section. This would correspond to about 10 active ligand-receptor complexes for half maximal activation. This number for the LH receptor is rather low. However, as discussed above the concentrations in the model are about 4-fold lower than in reality because we do not explicitly consider the restriction to the membrane. Moreover, receptors cluster on the membrane and thus increase their local concentration. The Hill constants of the FSH and estrogen receptors determine the slope of the LH expression kinetics in Figure $3 \mathrm{~B}$ and needed to be set to $K_{F}=500 \times 3 \mathrm{nM}$ and $K_{E}=35 \mathrm{nM}$ to reproduce the data. Also in case of the estrogen receptor the real cellular concentration will be higher because estrogen receptors move to the nucleus which has a smaller volume of about $250 \mu \mathrm{m}^{3}$ 
[59]. There is thus a further concentration by compartmentalization. While the IGF receptor concentration is low (1.7 nM IGF receptors [109]), the IGF receptor complex is used to approximate the activity of the aromatase which likely has a much higher concentration, given its cytoplasmic/nuclear localisation. We require $K_{I}=5 \mu \mathrm{M}$ to obtain a final estradiol concentration of $200-250 \mathrm{nM}$ in the follicular fluid. The value of $K_{I}$ only affects the rate of estradiol production, but none of the other kinetics as long as $I(0)=0.3 K_{I}$, and $\rho_{I}=3 K_{I} \delta_{I}$ are adapted accordingly.

\section{Numerical solution}

The PDEs were solved with finite difference methods (pdepe) as implemented in MATLAB. The robustness of the model to small parameter variations was assessed by simultaneously adding Gaussian noise to all parameter values. To this end 100 simulations were run with parameter values drawn from a Gaussian distribution with mean values equal to those in Table 1 and with standard deviation 0.2 and the standard deviation in model output was calculated and included as shaded area in all figures where it does not reduce readability.

\section{Results and discussion}

\section{Model consistency with data}

In summary, the model consists of 11 variables and 36 independent parameters in addition to the initial conditions, zero flux boundary conditions, the flux term $\Delta$, and the general Hill coefficient $n$ (Table 1). In spite of the large number of parameters, the model is very much constrained by experimental data. Thus, for more than three quarters (28) of these 36 parameters the values were set according to reported measurements (Table 1). These represent the measured affinities of the ligand-receptor interactions, the protein half-lifes, production rates, as well as the growth rate of the follicle. All initial conditions except for that of the IGF signalling complex, $I(0)$, were set to zero because we wanted the patterns to emerge from the regulatory interactions rather than being pre-set. $\mathrm{I}(0)$ was set as to reproduce the ordinate intercept in the LH expression kinetics in Figure 3A. The production rates that had not been directly measured as well as the response threshold of IGF signalling (Hill constant $K_{I}$ ) were set as to match the reported concentrations. All other response thresholds (Hill constants) could be inferred from the measured gene expression time courses (Figure 3). We set the response thresholds for LH signalling (Hill constant $K_{L}$ ) as to reproduce the slope in the time course of LH-receptor expression in the theca (Figure 3A) and the response thresholds for FSH and estrogen signalling (Hill constants $K_{F}$, and $K_{E}$ ) to reproduce the slope of the LH expression kinetics in the granulosa (Figure 3B). The activity of the FSH-/LHindependent expression of FSH receptors, $\vartheta$, was set as to obtain the ordinate intercept in the measured FSH receptor expression kinetics (Figure 3C).

The delay in the emergence of the expression of the LH-receptor and of aromatase activity in the granulosa (Figure 3B,D) is the result of the slow emergence of IGFreceptor complexes in the granulosa. The time scale on which IGF-receptor complexes emerge is determined by its turnover rate $\delta_{I}=1.2 \times 10^{-6} \mathrm{~s}^{-1}$. For a shorter half-life the delay would be shorter, while for a longer half-life the delay would be even longer. While this rate has been determined by several research groups, the measurements have all been carried out with cell lines that overexpressed the IGF receptor at levels more than 100fold higher than what has been observed in granulosa cells [47-49]. Moreover, the turnover rate was found to slow down as receptors become saturated by ligand [47-49]. As a result the experimentally determined rates of $2-8 \times$ $10^{-5} \mathrm{~s}^{-1}$ presumably reflect a maximal possible turnover rate, rather than a physiological turnover rate. Given the importance of this rate for the signalling processes in the follicle this rate should be measured again in the natural environment.

In spite of these limitations in the determination of $\delta_{I}$, we note that the measurements, although obtained by many independent research groups, are largely consistent and also reproduce additional data very well. One example is provided by the slope in Figure 3C, which is determined by the rate of FSH receptor expression, $\rho_{R f}$, a rate that was set to be equal to the measured value for the LH-receptor [41]. Further aspects are also reproduced very well (Figures 4,5 and 6) as discussed below.

While inaccuracies in the measurements are still possible, we note that the relative production and decay rates, the Hill constants, and the binding affinities are interdependent and inaccuracies in the directly measured parameter values are therefore largely compensated by the fitted parameters. As a result, we obtained similar results when we changed parameter values during the course of model development as long as we adjusted the 8 parameters discussed above such that the key characteristics were all still reproducable. Given the large number of parameters and studied outputs a global sensitivity analysis of such spatiotemporal model is impossible, in particular because, for the analysis to be informative, the 8 parameter values and the non-zero initial condition I( 0 ) that were not measured directly would always have to be adjusted such that the model output would still match the measured concentrations (Table 1) and expression kinetics (Figure 3). In a model of lung development we have previously added Gaussian noise to all parameter values to study the effect of simultaneous variations in several parameter values 
[104], and with a similar approach we find that the overall model behavior is robust in the presence of moderate noise levels; shaded areas are included in all Figures where it does not reduce readability to indicate the standard deviation in the model output to Gaussian noise with standard deviation of $20 \%$. Single parameter perturbations can be used to identify critical parameters, and such perturbations are particularly valuable when compared to similar experimental perturbations. No bovine transgenic data is available and murine folliculogenesis is very different [1].

\section{Hormone gradients in the follicle}

Initially no hormones or receptors (except for IGFreceptor complexes) are present in our model. LH and FSH then diffuse into the domain from the boundary. As shown in Figure 4A,B we observe the formation of a gradient of both FSH and LH. If we plot the gradient on a domain where the size of the growing domain is scaled with respect to the current length of the domain $\mathrm{L}(\mathrm{t})$, we notice that the relative extension of the gradients shrinks as the domain expands (Figure 4C,D).

An important aspect, so far neglected, is the formation of the antrum, a fluid-filled cavity within the follicle. In our 1D-model we captured this by including a fluid-filled part of our domain lacking cells and as such receptorfree (Figure $2 \mathrm{C}, \mathrm{D}$ ). As a result diffusion is unhindered in that part of the domain (shaded blue) and the gradients extend further from the source in the theca to the sink in the granulosa and cumulus oophorus-oocyte complex $(\mathrm{COC})$ (shaded grey) (Figure 4E,F). In fact, it is likely that the concentrations in the follicular fluid are homogenous since the aqueous fluid [121] will be mixed as the animal moves.

When we include such rapid mixing in the follicular fluid then the concentration gradients vanish in this compartment and the average concentrations in the follicular fluid increase (Figure 4G,H).

In both scenarios we predict a difference between the concentrations in the serum and in the follicular fluid (Figure 4E-H). The extent of this difference depends on how much hormone is bound by the receptors, and thus on the receptor concentration. The receptor concentration in turn depends on the size of the reaction volume, which we estimated to be some 500-fold smaller than the cell volume. For a smaller factor the concentration difference between follicular fluid and serum would be less pronounced. The bovine FSH concentrations have been reported to be similar in the serum $(0.7-2 \mathrm{nM})$ and in the follicular fluid $(0.6-2 \mathrm{nM})$, but the measured range is wide and the data were not acquired in the same animals $[55,58,110]$. In humans, such concentration differences between serum and follicular fluid has indeed been observed [122].

\section{Steroid production in the follicle}

Androgens are produced from steroid precursors in the theca or reach the theca via the capillary blood vessels surrounding the follicle [53]. Estradiol is produced only in granulosa $[7,98,123]$. In the simulation androgen production was therefore restricted to the theca, while production of estradiol was restricted to granulosa (Figure $5 \mathrm{~A}, \mathrm{~B}$ ). The simulation further predicts that within the granulosa layer estradiol production is strongest close to the theca where the positive impact of IGF signalling on aromatase expression would be stronger and the androgen concentration higher (Figure 5B).

From the theca androgens either diffuse into the follicle or are removed from the follicle via the blood circulation. Accordingly, the androgen concentration is the highest in the theca and falls towards the centre of the follicle (Figure 5C). Similarly, the estradiol concentration is the highest in the granulosa and falls towards the follicular fluid and the theca (Figure 5D). Interestingly, within the follicular fluid the androgen concentration is predicted to decline (Figure 5E) while the estradiol concentrations are predicted to rise (Figure $5 \mathrm{~F}$ ) as the follicle becomes larger. Similarly, the androstenedione concentration was found to decline from $107 \mathrm{nM}$ to $33 \mathrm{nM}$ and the testosterone concentration was found to decline from $100 \mathrm{nM}$ to $10 \mathrm{nM} \mathrm{[58].} \mathrm{In} \mathrm{the} \mathrm{same} \mathrm{experimental} \mathrm{study} \mathrm{the} \mathrm{estra-}$ diol concentration in the follicular fluid was found to rise from 17 to $230 \mathrm{nM}$ [58]. While the maximal testosterone concentration in the follicular fluid is determined by the precursor concentration and thus $\rho_{A}$ and the maximal concentration of estradiol in the follicular fluid is determined by the activity of the aromatase and thus by $K_{I}$, the decreasing testosterone and increasing estradiol concentrations themselves are not hard-coded and emerge from the regulatory interactions. It should be noted that while estradiol has been reported to downregulate testosterone production [82] in the model the decline in the testosterone concentration in the follicular fluid is observed without such negative feedback on its production.

\section{A self-emerging spatial organisation of receptor distributions}

The expression patterns of the FSH- and LH-receptor in bovine follicles over time have been reported $[15,16]$. FSH-receptors localize mainly to the granulosa [55] while $\mathrm{LH}$-receptor are first present close to the theca and emerge later in the granulosa $[15,16]$ with a declining gradient in LH-receptor expression towards the center of the follicle [83,124]. How this distribution emerges is not clear. The model now reveals that these observed receptor expression patterns result directly from the reported regulatory interactions. Thus, the model reproduces the high concentration of FSH-receptors in the granulosa 
cells (Figure 6A) and its much lower expression in the theca (Figure 5D). LH-receptors on the contrary initially mainly concentrate in the theca (Figure 6B,E, light blue line), later also in the granulosa and in the outer part of the COC (Figure 6B,E, green-red lines). The extent to which LH-receptors appear in the granulosa depends on the value of the Hill constant for the FSH-receptor, $K_{F}$ : the stronger the FSH-receptor signalling in the granulosa, the wider the LH-receptor distribution in the COC. Note that in Figure 6 we only show the subset of the domain that includes the theca, granulosa, COC and part of the follicular fluid.

Estrogen receptors are expressed in immature granulosa cells [95], but the expression of estrogen receptor-beta, the dominant form in the ovary, is mainly restricted to the granulosa cells of growing follicles [125,126]. Such a stronger expression in the granulosa emerges in our model as the result of the negative impact of FSH and LH signalling (via IGF signalling) on estrogen receptor expression. The stronger this feedback, the more restricted is the expression of the estrogen receptor to granulosa and COC (Figure 6C,F). We note that low expression levels of estrogen receptor in the theca are important to reproduce the physiological gene expression time course of LH-receptor expression. Some expression of the estrogen receptors in the theca has indeed been reported [127] and conditional knock-outs reveal an important role of estrogen receptor in the theca and absence of the receptor results in infertility in mice [126]. The mice are characterized by the presence of more antral follicles and failure to ovulate [126].

The FSH-receptor concentrations nicely demonstrate the consistency of the reported measurements. Even though the FSH-receptor expression rate $\rho_{R f}$ was set based on measured values and was thus not adapted to fit any particular feature of the model, the predicted FSHreceptor concentrations agree well with earlier measurements. Measurements in isolated granulosa cells reveal a density of 1500 FSH receptors by the secondary stage of follicular development and FSH-receptor numbers remains relatively constant during further development [50]. Available data in the human indicate that the number of FSH-receptors does not change during antral development, at least not until follicles reach a diameter of $12 \mathrm{~mm}$ [4]. Using a granulosa cell volume of $1140 \mu \mathrm{m}^{3}$ [59] $1500 \mathrm{FSH}$-receptors correspond to $2.2 \mathrm{nM}$ (and to $1100 \mathrm{nM}$ if we used the small membrane reaction volume of $2.5 \mu \mathrm{m}^{3}$ ). This concentration is indeed observed with a 2-fold increase at later stages in the parietal granulosa (Figure 6A,D). Such delayed 2-fold increase in FSHreceptor expression is also observed in experiments [128]. The IGF production rate was adjusted to reproduce the measured number of LH receptors in isolated rat granulosa cells which would correspond to $0.3 \mathrm{nM}$ if we use the entire cell volume or $150 \mathrm{nM}$ for the smaller membrane compartment (Figure 6B) [7]. In the in vitro experiments the LH receptor density increased some 10 -fold over 2 days in response to ligand stimulation [7]. A slow 10-fold increase in LH receptors also emerges from the regulatory interactions in the model (Figure 6E). The estrogen receptor expression rate was adjusted to obtain the typical estrogen receptor concentration of about $65 \mathrm{nM}$ (Figure 6C,F) [57].

While estrogen receptors are saturated at the ligand concentrations available in the follicle (Figure 6I,L), ligand-bound LH-receptors are rapidly internalized, and the concentration of ligand-bound LH-receptors is therefore much lower than the total LH-receptor concentration (Figure $6 \mathrm{H}, \mathrm{K}$ ). About one quarter of all FSH-receptors remain unbound (Figure 6G,J). Data from the hamster indicate that approximately $1 \%$ of the FSH serum concentration is tissue-bound within the ovary [129], but these measurements are difficult to compare to the simulation results.

It is an open question as to how the signalling responses of FSH- and LH-receptors differ. The differential activity in the model is the consequence of the combined effects of different spatial gradients, different ligand-receptor affinities and their different Hill constants. The downstream signalling effects of the active receptors are equivalent. The activity of FSH signalling is mainly restricted to the granulosa cells but also extends to the theca (Figure 6M). LH signalling on the contrary first concentrates in the theca and then expands to the granulosa (Figure 6N). Estrogen receptor activity extends throughout the granulosa and COC, and is somewhat lower in the theca (Figure 6O).

\section{Conclusion}

We have developed a 1D-computational model to integrate the large amount of published data dealing with bovine ovarian follicle development into a consistent spatio-temporal framework of ovarian folliculogenesis. A large amount of quantitative data is available that determined the parameter values in the constructed model (Table 1). As a result the model is highly constrained and reproduces biological observations, which were not explicitly included in the model and which were previously difficult to understand by simple verbal reasoning.

The spatio-temporal model reveals the importance of distances and gradients in the developing follicle. Because of the receptor-dependent removal of the hormones, their activity is strongly limited in fields of cells that express the receptor but not the ligand. Both human and bovine follicles grow to a similar final size of approximately $20 \mathrm{~mm}$. If the follicles were filled entirely with receptor expressing cells and if the oocyte were located in the center of the follicle, then the cells close to the oocyte 
would not receive any endocrine signalling (Figure 4C,D). This limitation is overcome by the emergence of a fluid filled cavity and the localization of the $\mathrm{COC}$ in the periphery of the follicle (Figure 2C,D). As a result high concentrations of the exogenous hormones reach the COC (Figure 4E,F), in particular if we also take rapid mixing of the hormones in the fluid-filled cavity into account (Figure 4G,H).

In agreement with earlier experimental data the model predicts that estradiol is produced mainly in the parietal granulosa layer (close to the theca) (Figure 5A,B), because here the androgen concentration is higher and the stimulating impact of IGF-receptor complexes, and FSH- and LH-signalling stronger (Figure 6M-O). Moreover, in agreement with earlier experimental observations the model predicts that the testosterone concentration in the follicular fluid declines while the estradiol concentration increases as the follicle grows and develops (Figure 5E,F). Overall, the receptor patterns emerging in the simulation closely match the observed expression patterns. This demonstrates that the observed expression patterns directly result from the reported regulatory interactions without need for further restrictions. Interestingly, MAPK-signalling has been shown to be required for the spatial propagation of LH-dependent signalling [130]. This is in good agreement with the model which requires IGF-dependent signalling for the emergence of LH-receptors in the granulosa.

We obtained these consistent results without requiring different signalling impacts of FSH and LH. Their differential impact in the model results entirely from the different expression patterns of their respective receptors, protein concentrations, binding affinities, diffusion constants, and signalling thresholds. It has previously been noticed that their intracellular signalling responses are virtually identical [65-69]. A similar case of where two homologous proteins take different roles even though they connect to the same signalling machinery has been reported for FGF4 and FGF8 during limb bud development. FGF4 and FGF8 have different roles, yet if the Fgf4 gene is expressed from the Fgf8-regulatory sequence instead of Fgf8 it can take over the function of FGF8 [131]. It is thus the differential spatio-temporal expression control rather than the differences on the protein level that convey the different functions.

With a data-based, validated model at hand it should now become feasible to investigate the molecular basis of infertility with a more integrated approach that reflects the tight coupling between the many regulatory processes. Most cases of primary ovarian insufficiency have remained unexplained so far. Future work should also focus on understanding species-specific differences. The model was mainly built with data from cattle, whereas all knock-out data originate from transgenic mouse models.
Murine follicles differ from bovine and human follicles in rapid maturation and small size with a diameter of only $0.5-0.6 \mathrm{~mm}$ at ovulation [1]. Given the small size of the murine follicles the diffusional gradients must be steeper to scale with the size of the domain. Here it is interesting to note that the affinity of human LH has been found to be about 100 -fold higher to rat LH-receptor than to human LH-receptor [37].

To further apply the model to human ovarian follicle development and infertility it will be important to establish all key parameters in human follicles as well and to develop a 3D-model. The diameters as well as the follicular fluid volume and granulosa cell numbers of growing human follicles have been reported previously $[13,14]$ and further measurements can now be made using the latest imaging technology, such as magnetic resonance imaging (MRI). Moreover, it is now increasingly feasible to obtain gene expression kinetics from in vivo and cultured follicles at defined stages and to manipulate in vitro cultured follicles. It will then be interesting to address the detailed impacts of changes in binding, decay, and production rates as decay rates and binding affinities are known to vary not only with age but also during the follicular phase of the menstrual cycle due to changes in the glycosylic moiety of the hormone [56,132]. In patients undergoing assisted reproduction the feedback with the pituitary is voluntarily disrupted. When active, this feedback leads to changes in the serum levels of FSH and LH in response to changes in estradiol secretion. To better understand the manifestation of disease it may become important to also include this feedback in the model rather than constant concentrations of FSH and LH.

Data-based, validated computational models of biomedical processes are still rare, but they are likely to become invaluable tools to define the molecular causes of disease and to develop novel therapeutic approaches that respect the complex regulatory logic of biological systems.

\section{Additional file}

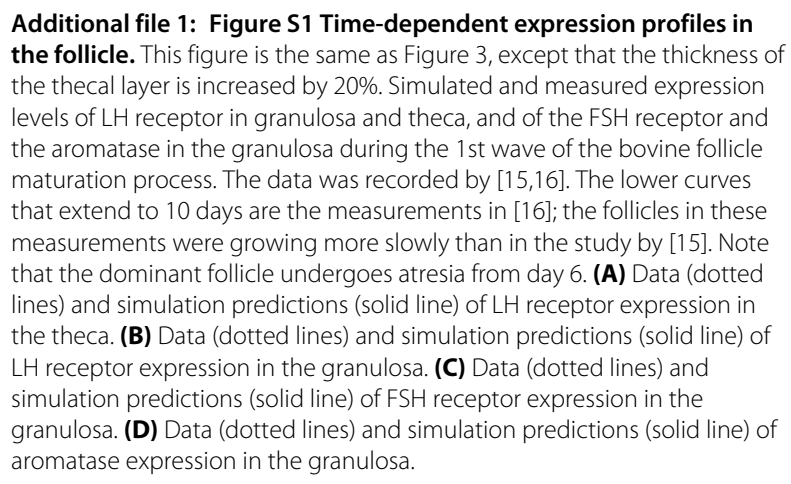


Additional file 2: Figure S2 FSH and LH gradient formation in the follicle. This figure is the same as Figure 4, except that the thickness of the thecal layer is increased by $20 \%$. At time zero no hormones are present in the follicle (black line). Over the next five days LH and FSH diffuse into the follicular domain from the boundary (theca) and form a gradient. The five time points are equally spaced at 0 (black), 1 (cyan), 2 (blue), 3 (green), 4 (yellow), and 5 days (red) curves. Panels A and B show the profiles on the growing domain. Panels $C$ and $D$ show the concentration profiles on a scaled domain. Panels $\mathrm{E}$ and $\mathrm{F}$ show the concentration profiles on a scaled domain if we include the fluid-filled antrum on one site of the COC block. Panels $\mathrm{G}$ and $\mathrm{H}$ show the concentration profiles on a scaled domain if we assume rapid mixing in the fluid-filled antrum. The shading indicates the different parts of the follicle, i.e. theca (white), granulosa cells (dark grey), cumulus cells (light grey), and follicular fluid (blue). Note that the theca and granulosa layers are very thin and thus barely visible.

\section{Additional file 3: Figure $\mathrm{S} 3 \mathrm{The}$ production of androgens and} estradiol in the follicle. This figure is the same as Figure 5, except that the thickness of the thecal layer is increased by $20 \%$. (A-B) Production of (A) androgens and (B) estradiol. Only part of the domain is shown, i.e. theca (white), granulosa cells (dark grey), and a part of the COC (light grey). (C-D) Concentration profiles of (C) androgens and (D) estradiol. The five time points are equally spaced at 0 (black), 1 (cyan), 2 (blue), 3 (green), 4 (yellow), and 5 days (red) curves. All panels show the concentration profiles on a scaled domain. The shading indicates the different parts of the follicle, i.e. theca (white), granulosa cells (dark grey), COC (light grey), and follicular fluid (blue). Androgens are produced only in the theca, and estradiol is produced only in the granulosa cells. In the follicular fluid steroids are neither produced nor degraded. (E-F) The average steroid concentrations of (E) androgens and (F) estradiol in the follicular fluid over time.

Additional file 4: Figure $\mathrm{S} 4 \mathrm{The}$ emergence of $\mathrm{FSH}-$, $\mathrm{LH}-$, and estrogen receptor gradients in the follicle. This figure is the same as Figure 6 , except that the thickness of the thecal layer is increased by 20\%. (A-C) Receptor profiles of (A) FSH-receptor, (B) LH-receptor, (C) estrogen receptor. At time zero the receptor concentrations are low and the receptors are distributed homogenously in the follicle (black line). Over the next five days localised feedbacks create a graded distribution of the

receptors. (D-E) Receptor production. (F-H) Unbound receptors (I-K) Bound receptors (L-N) Receptor activity. The five time points are equally spaced at 0 (black), 1 (cyan), 2 (blue), 3 (green), 4 (yellow), and 5 days (red) curves. All panels show the concentration profiles on a scaled domain. For better readability we only show the subset of the domain that includes the theca (white area), granulosa (dark shade), COC (light shade), and part of the follicular fluid (blue shade) on the right hand side of the domain.

\section{Competing interests}

The authors declare that they have no competing interests.

\section{Authors' contributions}

DI developed the model. DI and CDG wrote the paper. Both authors read and approved the final manuscript.

\section{Acknowledgements}

The authors thank Denis Menshykau and Mirjam Baechler for discussions.

\section{Author details}

${ }^{1}$ Department for Biosystems Science and Engineering (D-BSSE), ETH Zurich, Swiss Institute of Bioinformatics, Basel, Switzerland. ${ }^{2}$ Division of Gynecological Endocrinology and Reproductive Medicine, Women's Hospital, University of Basel, Basel, Switzerland.

Received: 22 November 2012 Accepted: 11 July 2013

Published: 15 July 2013

\section{References}

1. Griffin J, Emery BR, Huang I, Peterson CM, Carrell DT: Comparative analysis of follicle morphology and oocyte diameter in four mammalian species (mouse, hamster, pig, and human). J Exp Clin Assist Reprod 2006, 3:2

2. Aerts JMJ, Bols PEJ: Ovarian follicular dynamics: a review with emphasis on the bovine species. Part, I Folliculogenesis and pre-antral follicle development. Reprod Domest Anim = Zuchthygiene 2010, 45:171-179.

3. Lucy MC: The bovine dominant ovarian follicle. J Anim Sci 2007.

4. Gougeon A: Ovarian follicular growth in humans: ovarian ageing and population of growing follicles. Maturitas 1998, 30(2):137-142.

5. Richards JS, Pangas SA: The ovary: basic biology and clinical implications. J Clin Invest 2010, 120(4):963-972.

6. Kumar TR, Wang Y, Lu N, Matzuk MM: Follicle stimulating hormone is required for ovarian follicle maturation but not male fertility. Nat Genet 1997, 15(2):201-204.

7. Erickson GF, Wang C, Hsueh AJ: FSH induction of functional LH receptors in granulosa cells cultured in a chemically defined medium. Nature 1979, 279(5711):336-338

8. Vetharaniam I, Peterson A, McNatty K: Modelling female reproductive function in farmed animals. Anim Reprod Sci 2010, 120:1640-173.

9. Redding GP, Bronlund JE, Hart AL: Theoretical investigation into the dissolved oxygen levels in follicular fluid of the developing human follicle using mathematical modelling. Reprod, Fertil, Dev 2008, 20(3):408-417.

10. Redding GP, Bronlund JE, Hart AL: Mathematical modelling of oxygen transport-limited follicle growth. Reprod (Cambridge, England) 2007, 133(6):1095-1106.

11. Clark AR, Stokes YM: Follicle structure influences the availability of oxygen to the oocyte in antral follicles. Comput Math Methods Med 2011, 2011:287186.

12. Aerts JMJ, Bols PEJ: Ovarian follicular dynamics. A review with emphasis on the bovine species. Part, II Antral development, exogenous influence and future prospects. Reprod Domest Anim = Zuchthygiene 2010, 45:180-187.

13. Gougeon A: Dynamics of follicular growth in the human: a model from preliminary results. Human Reprod (Oxford, England) 1986, 1(2):81-87

14. McNatty KP: Hormonal correlates of follicular development in the human ovary. Aust J Biol SCi 1981, 34(3):249-268.

15. Bao B, Garverick HA: Expression of steroidogenic enzyme and gonadotropin receptor genes in bovine follicles during ovarian follicular waves: a review. J Anim Sci 1998, 76(7):1903-1921.

16. Xu Z, Garverick HA, Smith GW, Smith MF, Hamilton SA, Youngquist RS: Expression of follicle-stimulating hormone and luteinizing hormone receptor messenger ribonucleic acids in bovine follicles during the first follicular wave. Biol Reprod 1995, 53(4):951-957.

17. Singh J, Adams GP: Histomorphometry of dominant and subordinate bovine ovarian follicles. Anat Rec 2000, 258:58-70.

18. van Wezel IL, Krupa M, Rodgers RJ: Development of the membrana granulosa of bovine antral follicles: structure, location of mitosis and pyknosis, and immunolocalization of involucrin and vimentin. Reprod, Fertil, Dev 1999, 11:37-48.

19. Jeppesen JV, Kristensen SG, Nielsen ME, Humaidan P, Dal Canto M, Fadini R, Schmidt KT, Ernst E, Yding Andersen C: LH-Receptor gene expression in human granulosa and cumulus cells from antral and preovulatory follicles. J Clin Endocrino/ Metab 2012, 97(8):E1524-E1531.

20. Evans A: Physiology of follicle development in cattle. In Proceedings of the WBC Congress: (Quebec, Canada, 2004). [http://www.ivis.org/ proceedings/wbc/wbc2004/WBC2004-EvansAlex-simple.pdf]

21. $\angle I C H, P E D E R S E N ~ K O:$ Physicochemical characterization of pituitary follicle-stimulating hormone. J Gen Physiol 1952, 35(4):629-637.

22. STEELMAN SL, LAMONT WA, BALTES BJ: Preparation of highly active follicle stimulating hormone from swine pituitary glands. Acta Endocrinologica 1956, 22(2):186-190.

23. Yu SR, Burkhardt M, Nowak M, Ries J, Petrásek Z, Scholpp S, Schwille P, Brand M: Fgf8 morphogen gradient forms by a source-sink mechanism with freely diffusing molecules. Nature 2009 461(7263):533-536.

24. Dayel MJ, Hom EF, Verkman AS: Diffusion of green fluorescent protein in the aqueous-phase lumen of endoplasmic reticulum. Biophys J 1999, 76(5):2843-2851.

25. Niswender GD, Roess DA, Sawyer HR, Silvia WJ, Barisas BG: Differences in the lateral mobility of receptors for luteinizing hormone (LH) in the luteal cell plasma membrane when occupied by ovine LH versus human chorionic gonadotropin. Endocrinology 1985, 116:164-169. 
26. Schlessinger J, Shechter Y, Cuatrecasas P, Willingham MC, Pastan I: Quantitative determination of the lateral diffusion coefficients of the hormone-receptor complexes of insulin and epidermal growth factor on the plasma membrane of cultured fibroblasts. Proc Natl Acad SciU SA 1978, 75(11):5353-5357.

27. Ries J, Yu SR, Burkhardt M, Brand M, Schwille P: Modular scanning FCS quantifies receptor-ligand interactions in living multicellular organisms. Nature Methods 2009, 6(9):643-645.

28. Kumar M, Mommer MS, Sourjik V: Mobility of Cytoplasmic, Membrane, and DNA-Binding Proteins in Escherichia coli. Biophys 2010, 98(4):552-559.

29. Hebert B, Costantino S, Wiseman P: Spatiotemporal image correlation Spectroscopy (STICS) theory, verification, and application to protein velocity mapping in living CHO cells. Biophys $J 2005$ 88(5):3601-3614

30. Fersht A: Structure and Mechanism in Protein Science: A Guide to Enzyme Catalysis and Protein Folding: W. H. Freeman, 1999. ISBN 0716732688, 9780716732686.

31. Dias JA, Reeves JJ: Testicular FSH receptor numbers and affinity in bulls of various ages. $J$ Reprod Fertil 1982, 66:39-45.

32. Cheng K W: Properties of follicle-stimulating-hormone receptor in cell membranes of bovine testis. Biochem J 1975, 149:123-132.

33. Bhalla VK, Reichert LE: Properties of follicle-stimulating hormone-receptor interactions. Specific binding of human follicle-stimulating hormone to rat testes. J Biol Chem 1974, 249:43-51

34. Nakamura K, Krupnick JG, Benovic JL, Ascoli M: Signaling and phosphorylation-impaired mutants of the rat follitropin receptor reveal an activation- and phosphorylation-independent but arrestin-dependent pathway for internalization. J Biol Chem 1998 273(38):24346-24354.

35. Fletcher PW, Reichert LE: Cellular processing of follicle-stimulating hormone by Sertoli cells in serum-free culture. Mol Cell Endocrinol 1984, 34:39-49.

36. Aittomäki K, Lucena JL, Pakarinen P, Sistonen P, Tapanainen J, Gromoll J, Kaskikari R, Sankila EM, Lehväslaiho H, Engel AR, Nieschlag E, Huhtaniemi I, de la Chapelle A: Mutation in the follicle-stimulating hormone receptor gene causes hereditary hypergonadotropic ovarian failure. Cell 1995, 82(6):959-968.

37. Galet $C$, Ascoli M: The differential binding affinities of the luteinizing hormone (LH)/choriogonadotropin receptor for $\mathrm{LH}$ and choriogonadotropin are dictated by different extracellular domain residues. Mol Endocrinol (Baltimore, Md) 2005, 19(5):1263-1276.

38. Méster J, Rbertson DM, Feherty P, Kellie AE: Determination of high-affinity oestrogen receptor sites in uterine supernatant preparations. Biochem J 1970, 120(4):831-836.

39. Fry RC, Cahill LP, Cummins JT, Bindon BM, Piper LR, Clarke IJ: The half-life of follicle-stimulating hormone in ovary-intact and ovariectomized booroola and control merino ewes. J Reprod Fertil 1987, 81(2):611-615

40. Weick RF: A comparison of the disappearance rates of luteinizing hormone from intact and ovariectomized rats. Endocrinology 1977, 101:157-161.

41. Lloyd CE, Ascoli M: On the mechanisms involved in the regulation of the cell-surface receptors for human choriogonadotropin and mouse epidermal growth factor in cultured Leydig tumor cells. J Cell Biol 1983, 96(2):521-526

42. Nakamura K, Liu X, Ascoli M: Seven non-contiguous intracellular residues of the lutropin/choriogonadotropin receptor dictate the rate of agonist-induced internalization and its sensitivity to non-visual arrestins. J Biol Chem 2000, 275:241-247.

43. Woods MN, Gorbach SL, Longcope C, Goldin BR, Dwyer JT, Morrill-LaBrode A: Low-fat, high-fiber diet and serum estrone sulfate in premenopausal women. Am J Clin Nutr 1989, 49(6):1179-1183.

44. Ginsburg ES, Gao X, Shea BF, Barbieri RL: Half-life of estradiol in postmenopausal women. Gynecol Obstet Invest 1998, 45:45-48.

45. Singh AB, Norris K, Modi N, Sinha-Hikim I, Shen R, Davidson T, Bhasin S: Pharmacokinetics of a transdermal testosterone system in men with end stage renal disease receiving maintenance hemodialysis and healthy hypogonadal men. J Clin Endocrinol Metab 2001, 86(6):2437-2445
46. Valley CC, Solodin NM, Powers GL, Ellison SJ, Alarid ET: Temporal variation in estrogen receptor-alpha protein turnover in the presence of estrogen. J Mol Endocrinol 2008, 40:23-34.

47. Prager D, Yamasaki H, Weber MM, Gebremedhin S, Melmed S: Human insulin-like growth factor I receptor function in pituitary cells is suppressed by a dominant negative mutant. J Clin Invest 1992, 90(5):2117-2122

48. Prager D, Li HL, Yamasaki H, Melmed S: Human insulin-like growth factor I receptor internalization. Role of the juxtamembrane domain. J Biol Chem 1994, 269(16):11934-11937.

49. Backer JM, Shoelson SE, Haring E, White MF: Insulin receptors internalize by a rapid, saturable pathway requiring recepto autophosphorylation and an intact juxtamembrane region. J Cell Biol 1991, 115(6):1535-1545.

50. Findlay JK: An update on the roles of inhibin, activin, and follistatin as local regulators of folliculogenesis. Biol Reprod 1993, 48:15-23.

51. Jeppesen JV, Nielsen ME, Kristensen SG, Yding Andersen C: Concentration of activin $A$ and follistatin in follicular fluid from human small antral follicles associated to gene expression of the corresponding granulosa cells. Mol Cell Endocrinol 2012,

356(1-2):48-54.

52. Nielsen ME, Rasmussen IA, Kristensen SG, Christensen ST, Møllgård K, Wreford Andersen E, Byskov AG, Yding Andersen C: In human granulosa cells from small antral follicles, androgen receptor mRNA and androgen levels in follicular fluid correlate with FSH receptor mRNA. Mol Human Reprod 2011, 17:63-70.

53. Burger HG: Androgen production in women. Fertil Steril 2002 77(Suppl 4):S3-S5.

54. Sohl CD, Guengerich FP: Kinetic analysis of the three-step steroid aromatase reaction of human cytochrome P450 19A1. J Biol Chem 2010, 285(23):17734-17743.

55. Rhind SM, Bramley TA, Wright IA, McMillen SR: FSH and LH receptor concentrations in large ovarian follicles of beef cows in high and low levels of body condition at nine weeks post partum. Reprod, Fertil, Dev 1992, 4(5):515-522.

56. Wide L, Naessén T, Sundström-Poromaa I, Eriksson K: Sulfonation and sialylation of gonadotropins in women during the menstrual cycle, after menopause, and with polycystic ovarian syndrome and in men. J Clin Endocrinol Metab 2007, 92(11):4410-4417.

57. Bezwoda WR, Meyer K: Effect of alpha-interferon, 17 beta-estradiol, and tamoxifen on estrogen receptor concentration and cell cycle kinetics of MCF 7 cells. Cancer Res 1990, 50(17):5387-5391.

58. Henderson KM, MCNeilly AS, Swanston IA: Gonadotrophin and steroid concentrations in bovine follicular fluid and their relationship to follicle size. J Reprod Fertil 1982, 65(2):467-473.

59. Dhar A, Dockery P, O WS, Turner K, Lenton EA, Cooke ID: The human ovarian granulosa cell: a stereological approach. J Anat 1996, 188(Pt 3):671-676.

60. Armstrong DG, Gutierrez CG, Baxter G, Glazyrin AL, Mann GE, Woad KJ, Hogg CO, Webb R: Expression of mRNA encoding IGF-I, IGF-II and type 1 IGF receptor in bovine ovarian follicles. J Endocrinol 2000, 165:101-113.

61. Richards JS: Estradiol receptor content in rat granulosa cells during follicular development: modification by estradiol and gonadotropins. Endocrinology 1975, 97(5):1174-1184.

62. Schwall RH, Erickson GF: A new in vitro model system for the study of luteinizing hormone receptor down-regulation.. J Biol Chem 1983 258(6):3442-3445.

63. Shi $H$, Segaloff $D L$ : A role for increased lutropin/choriogonadotropin receptor (LHR) gene transcription in the follitropin-stimulated induction of the LHR in granulosa cells. Mol Endocrinol (Baltimore, Md) 1995, 9(6):734-744.

64. Zeleznik AJ, Midgley AR, Reichert LE: Granulosa cell maturation in the rat: increased binding of human chorionic gonadotropin following treatment with follicle-stimulating hormone in vivo. Endocrinology 1974, 95(3):818-825.

65. Fredriksson R, Lagerström MC, Lundin LG, Schioth HB: The G-protein-coupled receptors in the human genome form five main families. Phylogenetic analysis, paralogon groups, and fingerprints. Mol Pharmacol 2003, 63(6):1256-1272. 
66. Gloaguen P, Crépieux P, Heitzler D, Poupon A, Reiter E: Mapping the follicle-stimulating hormone-induced signaling networks. Front Endocrinol 2011, 2:45

67. Richards JS, Russell DL, Ochsner S, Hsieh M, Doyle KH, Falender AE, Lo YK Sharma SC: Novel signaling pathways that control ovarian follicular development, ovulation, and luteinization. Recent Prog Horm Res 2002, 57:195-220.

68. Simoni M, Gromoll J, Nieschlag E: The follicle-stimulating hormone receptor: biochemistry, molecular biology, physiology, and pathophysiology. Endocr Rev 1997, 18(6):739-773.

69. Wood JR, Strauss JF: Multiple signal transduction pathways regulate ovarian steroidogenesis. Rev Endocr Metab Disord 2002, 3:33-46.

70. Zhou J, Wang J, Penny D, Monget $P$, Arraztoa JA, Fogelson LJ, Bondy CA: Insulin-like growth factor binding protein 4 expression parallels luteinizing hormone receptor expression and follicular luteinization in the primate ovary. Biol Reprod 2003, 69:22-29.

71. Baxter RC: Insulin-like growth factor (IGF)-binding proteins: interactions with IGFs and intrinsic bioactivities. Am J Physiol. Endocrinol Metab 2000, 278(6):E967-E976.

72. Minegishi T, Hirakawa T, Kishi H, Abe K, Abe Y, Mizutani T, Miyamoto K: A role of insulin-like growth factor I for follicle-stimulating hormone receptor expression in rat granulosa cells. Biol Reprod 2000, 62(2):325-333.

73. Aad PY, Voge JL, Santiago CA, Malayer JR: ScienceDirect.com Domestic Animal Endocrinology - Real-time RT-PCR quantification of pregnancy-associated plasma protein-A mRNA abundance in bovine granulosa and theca cells: Effects of hormones in vitro. Domest Anim Endocrinol 2006, 31:357-372.

74. Firth SM, McDougall F, McLachlan AJ, Baxter RC: Impaired blockade of insulin-like growth factor I (IGF-I)-induced hypoglycemia by IGF binding protein-3 analog with reduced ternary complex-forming ability. Endocrinology 2002, 143(5):1669-1676.

75. Zhou J, Chin E, Bondy C: Cellular pattern of insulin-like growth factorI (IGF-I) and IGF-I receptor gene expression in the developing and mature ovarian follicle. Endocrinology 1991, 129(6):3281-3288.

76. Kapur S, Tamada H, Dey SK, Andrews GK: Expression of insulin-like growth factor-I (IGF-I) and its receptor in the peri-implantation mouse uterus, and cell-specific regulation of IGF-I gene expression by estradiol and progesterone. Biol Reprod 1992, 46(2):208-219.

77. Scheidegger KJ, Cenni B, Picard D, Delafontaine P: Estradiol decreases IGF-1 and IGF-1 receptor expression in rat aortic smooth muscle cells. Mechanisms for its atheroprotective effects. J Bio/ Chem 2000, 275(49):38921-38928.

78. Nair AK, Kash JC, Peegel H, Menon KMJ: Post-transcriptional regulation of luteinizing hormone receptor mRNA in the ovary by a novel mRNA-binding protein. J Bio/ Chem 2002, 277(24):21468-21473.

79. Themmen AP, Blok LJ, Post M, Baarends WM, Hoogerbrugge JW, Parmentier M, Vassart G, Grootegoed JA: Follitropin receptor down-regulation involves a cAMP-dependent post-transcriptional decrease of receptor mRNA expression. Mol Cell Endocrinol 1991, 78(3):R7-R13.

80. Schwall $R H$, Erickson GF: Inhibition of synthesis of luteinizing hormone (LH) receptors by a down-regulating dose of $\mathrm{LH}$. Endocrinology 1984, 114(4):1114-1123.

81. Hussein MO, Zipf WB: Temporal relationship of the prolactin-dependent $\mathrm{LH}$-induced $\mathrm{LH}$ receptor to the $\mathrm{LH}$ stimulus. J Cell Physiol 1988, 134:137-142.

82. Couse JF, Yates MM, Deroo BJ, Korach KS: Estrogen receptor-beta is critical to granulosa cell differentiation and the ovulatory response to gonadotropins. Endocrinology 2005, 146(8):3247-3262.

83. Eppig JJ, Wigglesworth K, Pendola F, Hirao Y: Murine oocytes suppress expression of luteinizing hormone receptor messenger ribonucleic acid by granulosa cells. Biol Reprod 1997, 56(4):976-984.

84. Matsui M, Sonntag B, Hwang SS, Byerly T, Hourvitz A, Adashi EY, Shimasaki S, Erickson GF: Pregnancy-associated plasma protein-a production in rat granulosa cells: stimulation by folliclestimulating hormone and inhibition by the oocyte-derived bone morphogenetic protein-15. Endocrinology 2004, 145(8):3686-3695.

85. Assou S, Anahory T, Pantesco V, Le Carrour T, Pellestor F, Klein B, Reyftmann L, Dechaud H, De Vos J, Hamamah S: The human cumulus-oocyte complex gene-expression profile. Human Reprod (Oxford, England) 2006, 21(7):1705-1719.

86. Hirakawa T, Minegishi T, Abe K, Kishi H, Ibuki Y, Miyamoto K: A role of insulin-like growth factor $I$ in luteinizing hormone receptor expression in granulosa cells. Endocrinology 1999, 140(11):4965-4971.

87. Knecht M, Darbon JM, Ranta T, Baukal AJ, Catt KJ: Estrogens enhance the adenosine 3', '5'-monophosphate-mediated induction of follicle-stimulating hormone and luteinizing hormone receptors in rat granulosa cells. Endocrinology 1984, 115:41-49.

88. Zhou J, Kumar TR, Matzuk MM, Bondy C: Insulin-like growth factor I regulates gonadotropin responsiveness in the murine ovary. Mol Endocrinol (Baltimore, Md) 1997, 11(13):1924-1933.

89. Wu YG, Bennett J, Talla D, Stocco C: Testosterone, not $5 \alpha$-dihydrotestosterone, stimulates LRH-1 leading to FSH-independent expression of Cyp19 and P450scc in granulosa cells. Mol Endocrinol (Baltimore, Md) 2011, 25(4):656-668.

90. Schreiber JR, Ross GT: Further characterization of a rat ovarian testosterone receptor with evidence for nuclear translocation. Endocrinology 1976, 99(2):590-596.

91. Drummond $A E$, Fuller $\mathrm{PJ}$ : The importance of ERbeta signalling in the ovary. J Endocrinol 2010, 205:15-23.

92. Salvetti NR, Acosta JC, Gimeno EJ, Müller LA, Mazzini RA, Taboada AF, Ortega $\mathrm{HH}$ : Estrogen receptors alpha and beta and progesterone receptors in normal bovine ovarian follicles and cystic ovarian disease. Vet Pathol 2007, 44(3):373-378.

93. Juengel $J$, Heath DA, Quirke LD, McNatty KP: Oestrogen receptor alpha and beta, androgen receptor and progesterone receptor mRNA and protein localisation within the developing ovary and in small growing follicles of sheep. Reproduction (Cambridge, England) 2006, 131:81-92.

94. Rosenfeld C: Intraovarian actions of oestrogen. Reproduction (Cambridge, England) 2001, 122(2):215-226.

95. Sharma SC, Clemens JW, Pisarska MD, Richards JS: Expression and function of estrogen receptor subtypes in granulosa cells: regulation by estradiol and forskolin. Endocrinology 1999, 140(9):4320-4334.

96. Mendoza RA, Enriquez MI, Mejia SM, Moody EE, Thordarson G: Interactions between IGF-I, estrogen receptor- $\alpha(\mathrm{ER} \alpha)$, and $\operatorname{ER} \beta$ in regulating growth/apoptosis of MCF-7 human breast cancer cells. J Endocrinol 2011, 208:1-9.

97. Berndtson AK, Vincent SE, Fortune JE: Low and high concentrations of gonadotropins differentially regulate hormone production by theca interna and granulosa cells from bovine preovulatory follicles. Biol Reprod 1995, 52(6):1334-1342.

98. Hunzicker-Dunn M, Maizels ET: FSH signaling pathways in immature granulosa cells that regulate target gene expression: branching out from protein kinase A. Cell Signal 2006, 18(9):1351-1359.

99. Richards JS, Jahnsen T, Hedin L, Lifka J, Ratoosh S, Durica JM, Goldring NB: Ovarian follicular development: from physiology to molecular biology. Recent Prog Horm Res 1987, 43:231-276.

100. Silva JM, Price CA: Insulin and IGF-I are necessary for FSH-induced cytochrome $\mathrm{P} 450$ aromatase but not cytochrome $\mathrm{P} 450$ side-chain cleavage gene expression in oestrogenic bovine granulosa cells in vitro. J Endocrinol 2002, 174(3):499-507.

101. Erickson GF, Garzo VG, Magoffin DA: Insulin-like growth factor-I regulates aromatase activity in human granulosa and granulosa luteal cells. J Clin Endocrinol Metab 1989, 69(4):716-724.

102. Hu Y, Ghosh S, Amleh A, Yue W, Lu Y, Katz A, Li R: Modulation of aromatase expression by BRCA1: a possible link to tissue-specific tumor suppression. Oncogene 2005, 24(56):8343-8348.

103. Celliere G, Menshykau D, Iber D: Simulations demonstrate a simple network to be sufficient to control branch point selection, smooth muscle and vasculature formation during lung branching morphogenesis. Biol Open 2012, 1(8):775-788.

104. Menshykau D, Kraemer C, Iber D: Branch Mode Selection during Early Lung Development. Plos Computat Biol 2012, 8(2:e1):002377.

105. Badugu A, Kraemer C, Germann P, Menshykau D, Iber D: Digit patterning during limb development as a result of the BMP-receptor interaction. Sci Rep 2012, 2:991. 
106. Baerwald AR, Adams GP, Pierson RA: Characterization of ovarian follicular wave dynamics in women. Biol Reprod 2003, 69(3):1023-1031.

107. Reichert LE, Dattatreyamurty B: The follicle-stimulating hormone (FSH) receptor in testis: interaction with FSH, mechanism of signal transduction, and properties of the purified receptor. Biol Reprod 1989, 40:13-26.

108. Choquet $D$, Triller $A$ : The role of receptor diffusion in the organization of the postsynaptic membrane. Nature Rev. Neurosci 2003, 4(4):251-265.

109. De Neubourg D, Robins A, Fishel S, Delbeke L: Quantification of insulin-like growth factor I receptors on granulosa cells with flow cytometry after follicular stimulation. Human Reprod (Oxford, England) 1998, 13:161-164.

110. Akbar AM, Reichert LE, Dunn TG, Kaltenbach CC, Niswender GD: Serum levels of follicle-stimulating hormone during the bovine estrous cycle. J Anim Sci 1974, 39(2):360-365.

111. Kaneko H, Watanabe G, Taya K, Sasamoto S: Changes in peripheral levels of bioactive and immunoreactive inhibin, estradiol-17 beta, progesterone, luteinizing hormone, and follicle-stimulating hormone associated with follicular development in cows induced to superovulate with equine chorionic gonadotropin. Biol Reprod 1992, 47:76-82.

112. Barnes MA, Kazmer GW, Bierley ST, Richardson ME, Dickey JF: Follicle stimulating hormone and estradiol-17 beta in dairy cows treated with progesterone-releasing intravaginal devices. J Dairy Sci 1980, 63:161-165.

113. Mihm M, Good TE, Ireland JL, Ireland JJ, Knight PG, Roche JF: Decline in serum follicle-stimulating hormone concentrations alters key intrafollicular growth factors involved in selection of the dominant follicle in heifers. Biol Reprod 1997, 57(6):1328-1337.

114. Reynolds LP, Kirsch JD, Kraft KC, Knutson DL, McClaflin WJ, Redmer DA: Time-course of the uterine response to estradiol-17beta in ovariectomized ewes: uterine growth and microvascular development. Biol Reprod 1998, 59(3):606-612.

115. Olivares A, Cárdenas M, Timossi C, Zariñán T, Díaz-Sánchez V, Ulloa-Aguirre A: Reactivity of different LH and FSH standards and preparations in the world health organization matched reagents for enzyme-linked immunoassays of gonadotrophins. Human Reprod (Oxford, England) 2000, 15(11):2285-2291.

116. Amballi A, Dada O, Adeleye A: Evaluation of the determination of reference ranges for reproductive hormones (prolactin, $\mathrm{FSH}, \mathrm{LH}$, and testosterone) using enzyme immunoassay method. Sci Res Essay 2007.

117. Laven JSE, Fauser BCJM: What role of estrogens in ovarian stimulation. Maturitas 2006, 54(4):356-362.

118. Selvaraj N, Moudgal NR: Development of an LH receptor assay capable of measuring serum LH/CG in a wide variety of species. J Reprod Fertil 1993, 98(2):611-616.

119. Larsen WJ, Tung HN, Polking C: Response of granulosa cell gap junctions to human chorionic gonadotropin (hCG) at ovulation. Biol Reprod 1981, 25(5):1119-1134.

120. Iber D, Campbell ID: Integrin activation-the importance of a positive feedback. Bull Math Biol 2006, 68(4):945-956.

121. Rodgers RJ, Irving-Rodgers HF: Formation of the ovarian follicular antrum and follicular fluid. Biol Reprod 2010, 82(6):1021-1029.

122. Stone BA, Serafini PC, Batzofin JH, Quinn P, Kerin JF, Marrs RP: Interrelationships between plasma hormone levels and the content of total protein, gonadotropins and steroid hormones in antral fluids of women undergoing in vitro fertilization. Fertil Steril 1988, 50:102-109.

123. Richards JS, Hickey GJ, Chen SA, Shively JE, Hall PF, Gaddy-Kurten D, Kurten R: Hormonal regulation of estradiol biosynthesis, aromatase activity, and aromatase mRNA in rat ovarian follicles and corpora lutea. Steroids 1987, 50(4-6):393-409.

124. Meduri G, Vuhai-Luuthi MT, Jolivet A, Milgrom E: New functional zonation in the ovary as shown by immunohistochemistry of luteinizing hormone receptor. Endocrinology 1992, 131:366-373.

125. Haydon $\downarrow$, Juengel $J$, Thomson BP, Eckery DC: Expression of mRNAs encoding oestrogen receptor (ER) alpha and ERbeta, androgen receptor and progesterone receptor during gonadal and follicular development in the marsupial brushtail possum (Trichosurus vulpecula). Reprod, Fertil, Dev 2008, 20(3):335-349.

126. Lee S, Kang DW, Hudgins-Spivey S, Krust A, Lee EY, Koo Y, Cheon Y, Gye MC, Chambon P, Ko C: Theca-specific estrogen receptor-alpha knockout mice lose fertility prematurely. Endocrinology 2009, 150(8):3855-3862

127. Taylor AH, Al-Azzawi F: Immunolocalisation of oestrogen receptor beta in human tissues. J Mol Endocrinol 2000, 24:145-155.

128. Kawashima I, Okazaki T, Noma N, Nishibori M, Yamashita Y, Shimada M: Sequential exposure of porcine cumulus cells to $\mathrm{FSH}$ and/or $\mathrm{LH}$ is critical for appropriate expression of steroidogenic and ovulation-related genes that impact oocyte maturation in vivo and in vitro. Reproduction (Cambridge, England) 2008, 136:9-21.

129. Sheela Rani CS, Moudgal NR: Measurement of FSH in the ovarian tissue by radioimmunoassay: correlation to serum FSH levels and follicular development in the hamster. Mol Cell Endocrinol 1978, 11(3):293-307.

130. Hsieh M, Thao K, Conti M: Genetic dissection of epidermal growth factor receptor signaling during luteinizing hormone-induced oocyte maturation. PLOS ONE 2011, 6(6):e21574.

131. Lu P, Minowada G, Martin GR: Increasing Fgf4 expression in the mouse limb bud causes polysyndactyly and rescues the skeletal defects that result from loss of Fgf8 function. Development (Cambridge, England) 2006, 133:33-42.

132. Mason M, Fonseca E, Ruiz JE, Morán C, Zárate A: Distribution of follicle-stimulating hormone and luteinizing hormone isoforms in sera from women with primary ovarian failure compared with that of normal reproductive and postmenopausal women. Fertil Steril 1992, 58:60-65.

doi:10.1186/1752-0509-7-60

Cite this article as: Iber and De Geyter: Computational modelling of bovine ovarian follicle development. BMC Systems Biology 2013 7:60.

Submit your next manuscript to BioMed Central and take full advantage of:

- Convenient online submission

- Thorough peer review

- No space constraints or color figure charges

- Immediate publication on acceptance

- Inclusion in PubMed, CAS, Scopus and Google Scholar

- Research which is freely available for redistribution 